\section{InI)ret}

3.2020

Adán Nieto Martín

Universidad de Castilla-La

Mancha

\title{
Hacia un Derecho penal económico europeo de los Derechos humanos
}

\begin{abstract}
Sumario
El trabajo propone la aparición de un nuevo sector dentro del Derecho penal económico cuyo objetivo sería la protección de los Derechos humanos y la sanción de las empresas multinacionales. Este nuevo sector debiera estar impulsado por la UE, que en los últimos años y a partir de diversas fuentes ha ido promulgando un conjunto de directivas y reglamentos que inciden en este ámbito. El Derecho penal de los Derechos humanos vendría a complementar las posibilidades que hoy ya ofrece el Derecho penal internacional para sancionar estas conductas. El fundamento de las nuevas incriminaciones que se encuentra en este trabajo conecta con las obligaciones de cumplimiento normativo (due diligence) que se han establecido en los Principios rectores de Naciones Unidas para empresas multinacionales e igualmente con los nuevos deberes de transparencia vinculados con la información no financiera.
\end{abstract}

\begin{abstract}
The work proposed the emergence of a new sector within economic criminal law whose objective would be the protection of human rights and the sanctioning of multinational companies. This new sector should be promoted by the EU, which in recent years and from various sources has been enacting a set of directives and regulations that affect this area. The economic criminal law of human rights would complement the possibilities already offered by international criminal law to sanction these conducts. The basis of the new incriminations found in this work connects with the obligations to establish compliance measures (due diligence) that have been established in the United Nations Guiding Principles for Multinational Enterprises and also with the new duties of transparency linked to non-financial information.
\end{abstract}

\begin{abstract}
Die Arbeit stellt die Entwicklung eines neuen Sektors innerhalb des Wirtschaftsstrafrechts vor, dessen Ziel der Schutz der Menschenrechte und die Sanktionierung von multinationalen Unternehmen ist. Dieser neue Sektor sollte von der EU gefördert werden, die in den letzten Jahren eine Reihe von Richtlinien und Verordnungen erlassen hat, die diesen Bereich betreffen. Das Wirtschaftsstrafrecht der Menschenrechte würde die bereits durch das Völkerstrafrecht bestehenden Möglichkeiten zur Sanktionierung dieser Verhaltensweisen ergänzen. Die Grundlage der in dieser Arbeit vorgeschlagenen neuen Straftatbestände liegt in den Verpflichtungen zur Festlegung von Compliance Maßnahmen, die in den Leitprinzipien der Vereinten Nationen für multinationale Unternehmen festgelegt wurden, sowie in den neuen Transparenzverpflichtungen im Zusammenhang mit nichtfinanziellen Informationen.
\end{abstract}

Title: Towards an European economic criminal law in human rights

Titel: Auf dem Weg zu einem europäischen Wirtschaftsstrafrecht der Menschenrechte

Palabras clave: empresas multinacionales y derechos humanos, cumplimiento normativo, información no financiera, responsabilidad penal de personas jurídicas 
Keywords: multinational companies and human rights, compliance in human rights, nonfinancial information, criminal liability of legal entities

Stichwörter: multinationale Unternehmen und Menschenrechte, compliance in Menschenrechte, nicht-finanzielle Informationen, strafrechtliche Verantwortlichkeit juristischer Personen

DOI: $10.31009 /$ InDret.2020.i3.05 


\section{InI)ret}

3.2020

Recepción

$13 / 04 / 20$

Aceptación

08/05/20

\section{Índice}

1. Derecho penal económico de los DDHH v. Derecho penal internacional económico

2. Los límites del Derecho penal internacional económico

3. El Derecho penal económico europeo de los Derechos humanos

3.1 La protección de los Derechos humanos como objeto de la regulación de la actividad empresarial

a. Cumplimiento normativo en Derechos humanos

b. La respuesta en los ordenamientos nacionales

c. La regulación europea del comportamiento empresarial en materia de Derechos humanos

3.2 Delitos y penas en el Derecho penal económico europeo de los DDHH

a. Receptación de bienes o servicios producidos con violaciones a los DDHH

b. Embargos y exportaciones condicionadas al cumplimiento de deberes de due diligence

c. Incumplimiento genérico de las obligaciones de due diligence

d. La falsedad en el balance no financiero

e. La responsabilidad de los certificadores y auditores

f. La competencia de la UE

\section{Bibliografía}

Este trabajo se publica con una licencia Creative Commons Reconocimiento-No Comercial 4.0 Internacional@) @() (3) 


\section{Derecho penal económico de los DDHH v. Derecho penal internacional económico*}

En los últimos años la UE ha publicado dos normas que establecen obligaciones de las empresas, especialmente multinacionales, destinadas a garantizar que su actividad sea respetuosa con los Derechos humanos; me refiero concretamente el Reglamento 2017/821 relativo a la exportación de minerales procedentes de zonas de conflicto ${ }^{1}$ y a la Directiva 2014/95 sobre información no financiera. ${ }^{2}$ Ambos textos forman parte de una incipiente estrategia que parte de la existencia de obligaciones positivas de las empresas hacia los Derechos humanos. El Reglamento relativo a los “minerales en zonas de conflicto” obliga a las empresas importadoras de determinados minerales a velar porque sus proveedores a lo largo de la cadena de suministro respeten los Derechos humanos, imponiéndoles obligaciones de due diligence. En la extracción de estos minerales son frecuentes los trabajos forzados, la trata de personas o su comercio sirve para la financiación de grupos armados, la corrupción o el blanqueo de capitales. La Directiva sobre los "estados no financieros" establece obligaciones de transparencia: las grandes empresas deben informar de cuáles son precisamente las medidas que está adoptando para cumplir con su obligación de respetar los Derechos humanos, el medio ambiente o la corrupción. Esta nueva estrategia basada en el cumplimiento normativo y la transparencia proceden en gran parte de los Principios Rectores de Naciones Unidas sobre empresas multinacionales y Derechos humanos, que la UE recogió a través de la Estrategia renovada de la UE para 2011-2014 sobre la responsabilidad social de las empresas ${ }^{3}$ y el Plan de Acción de la UE para los Derechos humanos y la Democracia aprobado en 2012. ${ }^{4}$

Aunque los Principios rectores de Naciones Unidas hacen referencia a la necesidad de utilizar el Derecho penal con el fin de castigar las violaciones a los Derechos humanos, ${ }^{5}$ las normas europeas antes citadas no han tomado posición alguna al respecto, dejando abierto el modo en que debe sancionarse la infracción a sus disposiciones. El objetivo principal de este trabajo consiste, precisamente, en ofrecer una primera reflexión acerca de cómo conformar la intervención penal en esta materia (supra 3.2). Para ello se proponen una serie de tipos penales, pertenecientes al Derecho penal económico, que podrían ser objeto de armonización, a

\footnotetext{
* Autor de contacto: Adán Nieto Martín, adan.nieto@uclm.es. El trabajo se inscribe en el Proyecto de Investigación financiado por el Ministerio de Economía, Industria y Competitividad: "Responsabilidad penal de las empresas multinacionales por violaciones a los derechos humanos y al medio ambiente" (DER2017/85144-C2-1-P).

${ }^{1}$ Reglamento (UE) 2017/821 del Parlamento Europeo y del Consejo, de 17 de mayo de 2017, por el que se establecen obligaciones en materia de diligencia debida en la cadena de suministro por lo que respecta a los importadores de la Unión de estaño, tantalio y wolframio, sus minerales y oro originarios de zonas de conflicto o de alto riesgo.

2 Directiva 2014/95/UE del Parlamento Europeo y del Consejo, de 22 de octubre de 2014, por la que se modifica la Directiva 2013/34/UE en lo que respecta a la divulgación de información no financiera e información sobre diversidad por parte de determinadas grandes empresas y determinados grupos.

${ }^{3}$ Comunicación de la Comisión al Parlamento Europeo, al Consejo, al Comité económico y social europeo y al Comité de las Regiones, Estrategia renovada de la UE para 2011-2014 sobre la responsabilidad social de las empresas.

4 Consejo de la Unión Europea, EU Action plan on human rights and democracy (https://www.consilium.europa.eu/media/30003/web_en_actionplanhumanrights.pdf).

${ }^{5}$ Cfr. Principios rectores sobre las empresas y los Derechos Humanos, Naciones Unidas, Oficina del Alto Comisionado, 2011, p. 3: "los Estados pueden estar incumpliendo sus obligaciones internacionales de derechos humanos cuando se les puedan atribuir esas violaciones o cuando no adopten las medidas adecuadas para prevenir, investigar, castigar y reparar los abusos cometidos por agentes privados”.
} 
partir de la competencia aneja prevista en el art. 83.2 del TFUE. Estos tipos penales complementarían al Derecho penal internacional económico, que en los últimos años está siendo objeto de una renovada atención doctrinal. ${ }^{6}$ Dicho en términos generales, su función consistiría en sancionar el incumplimiento de obligaciones positivas, de protección, mientras que el Derecho penal internacional, sancionaría el incumplimiento de las obligaciones negativas, de no afectación o lesión a los Derechos humanos.

En la primera parte de este trabajo se expondrán las características fundamentales y los límites que el Derecho penal internacional tiene para la sanción de violaciones de Derechos humanos realizadas por empresas multinacionales (Vid. 2). De hecho, como es conocido, la gran protagonista en este terreno ha sido hasta tiempos bien recientes una norma nacional de carácter civil, la Alien Tort Claim Act, un texto de finales del siglo XVIII que permite interponer reclamaciones ante los tribunales de los EEUU cuando se ha violado the law of the nations, es decir una norma perteneciente al ius cogens internacional. ${ }^{7}$ A partir del caso Unocal (1997), la ATCA fue utilizada para interponer numerosas demandas civiles en los Estados Unidos contra empresas multinacionales. ${ }^{8}$ La desactivación por parte de la Corte Suprema de la ATCA a través de los casos Kiobel ${ }^{9}$ y Jesner ${ }^{10}$ hace especialmente urgente, de un lado, reavivar el Derecho penal

${ }^{6}$ Sobre todo, por parte de la doctrina alemana AMBOS, Derecho penal internacional económico, 2018 (=
AMBOS/BocK, Aktuelle und grundsätzliche Frages des Wirtschaftsvölkerstrafrecht, 2018
JeßBERGER/KALECK/SINGELNSTEIN (eds.), Wirtschaftsvölkerstrafrecht, 2015; SCHMIDT, Crimes of Business in
International Law, 2015; KRAJEWSKI/OEHM/SAAGE-MAAß, Zivil- und Strafrechtliche
Unternehmensverantwortung für Menchenrechtsverletzungen, 2018. Es también importante el número
monográfico dedicado a esta materia AMBOS/CARSTEN (eds.), «Special Issue: Human Rights Compliance and
Corporate Criminal Liability», Criminal Law Forum, (4), 2018, pp. 495 ss. En Austria THURNER,
Internationales $\quad$ Unternehmensstrafrecht, Konzerverantwortlichkeitkeit für Menschenrechtsverletzungen, 2012. En España, Demetrio CRESPO/Nieto MARTín (dirs.), Derecho penal económico y Derechos humanos, 2018; PÉrez CEPEDA, «Hacia el final de la impunidad de las empresas transnacionales por violación de Derechos Humanos», Revista Penal, (44), 2019, pp. 126 ss. La AIDP ha dedicado también la Sección I de su XX Congreso Internacional a este tema, MANACORdA/MARletTA/VANACORE (eds.), «Individual Liability for Business Involvement in International Crimes», RIDP, (1), 2017.

${ }^{7}$ La bibliografía sobre la Alien Torts Claims Act es muy extensa, por todos JosePH, Corporations and Transnational Human Rights Litigations, 2004.

${ }^{8}$ El caso Doe v. Unocal, 395 F.3d 932 (9th Cir. 2002), contiene todos los ingredientes de la responsabilidad de las multinacionales en materia de Derechos humanos: la violación tiene lugar en Birmania y la empresa participaba a través de una joint venture en una explotación petrolera, donde la empresa local utilizaba mano de obra esclava. El caso se abre por considerar que Unocal conocía y se beneficiaba de esta violación. Finalmente, en el año 2000, se rechaza el caso por considerar que el mero conocimiento de estas circunstancias, sin una participación activa no era suficiente para hablar de participación. Para llegar a esta conclusión, el Tribunal cita expresamente los casos de Nüremberg Flick y Krupp donde la utilización de mano de obra esclava fue la más utilizada, o al menos exitosa en las condenas. Este caso provocó una intensa discusión doctrinal acerca de la categoría de la complicidad empresarial y abrió grandes expectativas para plantear demandas ante los tribunales americanos. Sobre la importancia de Uocal, por ejemplo, Thompson/Ramasastry/TAYlor, «Translating Unocal: The Expanding Web Of Liability For Business Entities Implicated In International Crimes», The Geo. Wash. Int'l L. Rev, (40), 2009, pp. 841 ss.

${ }^{9}$ Kiobel v. Real Dutch Petroleum Co., 569 U.S. 108. En el caso Kiobel los demandantes son nigerianos y reclaman que la empresa petrolera holandesa, Shell, a través de su filial nigeriana realizó conjuntamente con el gobierno nigeriano violaciones de Derechos humanos. La Corte Suprema decidió que la ATCA no era de aplicación extraterritorial, por lo que tenía que existir un nexo substancial con los Estados Unidos, para afirmar la jurisdicción. Cfr. CASSEL, «Suing Americans For Human Rights Torts Overseas: The Supreme Court Leaves The Door Open», Notre Dame Law Review, (4), 2010, pp. 1773 ss., donde puede encontrarse el debate que suscitó esta sentencia; CASSEL, «Corporate Aiding and Abetting of Human 
internacional económico, pero también buscar ulteriores desarrollos basados en el incumplimiento de obligaciones como las previstas en las normas europeas. ${ }^{11}$

\section{Los límites del Derecho penal internacional económico}

El Derecho penal internacional económico nace con Nüremberg. Su función consiste en establecer la responsabilidad de los dirigentes y directivos empresariales por graves violaciones a Derechos humanos que se tipifican en los denominados core crimen (genocidio, lesa humanidad, crímenes de guerra y de agresión). A estos últimos podrían añadirse otra serie de delitos internacionales como la tortura, los trabajos forzados o la esclavitud. ${ }^{12}$ Desde los históricos juicios contra los industriales alemanes, por su cooperación con el régimen nacionalsocialista, el Derecho penal internacional ha abordado la responsabilidad de directivos y empleados de manera tópica, a partir de la construcción de grupos de casos. De las diversas clasificaciones, la que más nos interesa es aquella que va de una mayor a menor implicación de la empresa en los hechos. De acuerdo con esta clasificación existirían cuatro grupos de casos. ${ }^{13}$

El primero de ellos incluye los supuestos en que los directivos o empleados de la empresa son autores o coautores de un delito perteneciente a los core crime del Derecho penal internacional. El ejemplo podría ser la utilización de trabajo esclavo, como ocurrió con algunas empresas españolas durante el primer franquismo ${ }^{14} \mathrm{o}$ en el caso Unocal, ${ }^{15} \mathrm{o}$ las violaciones del Derecho internacional humanitario realizadas por los empleados de Blackwater. ${ }^{16}$ En estos supuestos la responsabilidad individual plantea principalmente el problema de la responsabilidad de los superiores, cuando no han participado activamente en los hechos. Aunque pueda afirmarse una posición de garantía, y por tanto recurrir a la comisión por omisión, normalmente existirán

Rights Violations: Confusion in the Courts», Northwestern Journal Of International Human Rights, (6), 2008, pp. 1 ss.

${ }^{10}$ Jesner et al. V. Arab Bank, PLC, 585 U.S (2018). El caso también pertenece al ámbito de la complicidad empresarial: los demandantes, un grupo de víctimas israelitas, indican que el Arab Bank, una institución financiera jordana, con sucursales en EEUU había financiado ilegalmente a la organización terrorista que atentó contra ellos. La conexión con el territorio norteamericano se producía, según los demandantes, porque el banco utilizó su filial americana con el objetivo de financiar a la organización, así como para el blanqueo de capitales. En este caso, además del debate sobre la existencia o no de una vinculación suficiente con la jurisdicción norteamericana, la Corte Suprema cierra un debate, de gran importancia en el marco de este trabajo, relativo a la responsabilidad penal de las personas jurídicas como parte de las law of nations. Esta cuestión que ya había sido debatida en Kiobel, se cierre ahora por la Corte Suprema negando que constituya parte del ius cogens internacional. Son muy interesantes los análisis que los jueces Sotomayor y Kennedy hacen de la cuestión de la responsabilidad penal de las personas jurídicas a lo largo de la sentencia.

${ }^{11}$ Una panorámica de los distintos casos que han tenido como protagonistas a empresas sobre la base del Derecho penal internacional, en KALECK, «Die Verantwortung von Unternehmen und Unternehmern für Völkerrechtsverbrechen -die Nüremberg Prozessen», en JEßBERGER/KALECK/SINGELNSTEIN (eds.), Wirtschaftsvölkerstrafrecht, 2015, pp. 83 ss. Con información muy detallada de distintos países vid. los diversos informes nacionales en MANACORDA /MARLETTA/VANACORE (eds.), RIDP, (1), 2017, y MANACORDA, «General Report on Individual Liability for Business Involvement in International Crimes», en MANACORDA/Marletta/VANACORE (eds.), RIDP, (1), 2017, pp. 22 ss.

${ }^{12} \mathrm{Cfr}$. Ambos, Derecho penal internacional económico, 2018, p. 23.

13 Cfr. Ambos, Derecho penal internacional económico, 2018, pp. 31 ss.; MANACORDA, en MANACORda/Marletta/VAnacore (eds.), RIDP, (1), 2017, pp. 13 ss.

${ }^{14}$ Vid. LAFUENTE, Esclavos por la patria. La explotación de los presos bajo el franquismo, 2002.

${ }^{15}$ Vid. supra n. 8.

${ }^{16}$ Vid. SCAHILL, Blackwater: el auge del ejército mercenario más poderoso del mundo, 2008. 
problemas en el tipo subjetivo para demostrar el conocimiento y por tanto la tolerancia del hecho. ${ }^{17}$

Este problema, que es común a todo el Derecho penal de la empresa, reviste una especial complejidad en los casos característicos de las violaciones a Derechos humanos. Las violaciones suelen ocurrir a miles de kilómetros de distancia de los cuarteles generales de las empresas y además las infracciones suelen llevarse a cabo no por empleados de la empresa matriz, sino normalmente por filiales locales, constituidas a veces como joint ventures. ${ }^{18}$ Cuanto más proximidad existe entre los hechos, sus autores más cercanos y los dirigentes empresariales más fácil resulta adaptar la aportación empresarial a las necesidades del caso concreto y probar además que los superiores lo conocían. ${ }^{19}$

Como ocurre también en el Derecho penal de la empresa, la responsabilidad del superior se ve obstaculizada por el sistema de delegaciones dentro de la entidad. ${ }^{20}$ Mas aquí también la lejanía física entre el superior y los hechos aumenta la posibilidad de que exista una amplia cadena de delegaciones, que imposibilite establecer la responsabilidad del superior. A lo sumo este tendrá normalmente un deber muy genérico de supervisión. ${ }^{21}$ Con el fin de resolver estos casos, podrían ser de utilidad teorías como la del dominio de la organización para fundamentar casos de autoría mediata. Mas los problemas son también relevantes. Si ya es difícil demostrar el dominio de la organización en el marco de una empresa, lo es todavía más cuando se pretende proyectar esta teoría sobre el dominio de la cadena de suministro, ${ }^{22}$ la empresa filial o la joint venture. ${ }^{23}$

${ }^{17}$ Cfr. al respecto AmBos, Derecho penal internacional económico, 2018. pp. 104 ss.; MANACORDA, en MANACORDA/MARLETtA/VANACORE (eds.), RIDP, (1), 2017, p. 49 (aunque refiriéndose a la participación); WiтTiG, «Zur Legitimation und Grenzen eines rechtsstastaatlichen Wirtschaft», en JEßBERGER/KALECK/SINGELNSTEIN (eds.), Wirtschaftsvölkerstrafrecht, 2015, pp. 246 ss. El art. 28 del Estatuto de Roma prevé la responsabilidad de los superiores, pero limitada a los jefes militares. Este precepto es similar a una cláusula de comisión por omisión específica, que plantea problemas similares al deber de garantía. Sobre la posibilidad, negada mayoritariamente, de aplicarlo a los dirigentes empresariales vid. detalladamente GARROCHO SALCEDO, La responsabilidad del superior por omisión en el Derecho penal internacional, 2016, pp. 131 ss.; MARLETTA, «Heads of Business and the framework of Liability for complicity under International Criminal Law», en MANACORDA/MARLETTA/VANACORE (eds.), RIDP, (1), 2017, pp. 91 ss.; SснмiDT, Crimes of Business in International Law, 2016, pp. 326 ss.

18 Cfr. Ambos, Derecho penal internacional económico, 2018, pp. 112 s., WitTig, en JEßBEERGER/KALECK/SINGELNSTEIN (eds.), Wirtschaftsvölkerstrafrecht, 2015, pp. $248 \mathrm{~s}$.

${ }^{19} \mathrm{Cfr}$. Manacorda, en Manacorda/Marletta/VANacore (eds.), RIDP, (1), 2017, p. 46.

${ }^{20} \mathrm{Al}$ respecto ampliamente LASCURAIN SÁNCHEZ, «Tema 3. La responsabilidad penal individual en los delitos de empresa», en De La Mata/Dopico/Lascuraín/Nieto, Derecho penal económico y de la empresa, 2018, pp. 104 ss.

${ }^{21}$ Cfr. WitTig, en JeßBERGER/KALECK/SingeLnSTEIN (eds.), Wirtschaftsvölkerstrafrecht, 2015, pp. 250 ss., quien mantiene que en weak governance zones la dirección de la empresa tiene un deber de supervisión especial.

${ }^{22}$ Un caso discutido en relación a proveedores ha sido en Alemania el de la empresa KiK. En los locales de uno de sus proveedores en Pakistán se originó un incendió que acabó con la vida de 259 personas y ocasionó 47 heridos graves. Este proveedor suministraba el $70 \%$ de su producción a la filial alemana, por lo que su dependencia era absoluta. En este caso, desde el punto de vista civil el problema se encontraba en la ausencia de repercusión patrimonial para la matriz, vid. HüBNER, «Human Rights Compliance um Haftung im Außenverhältnis», en KrajeWsK/SAaGe MAAB (eds.), Die Durchsetzung menschenrechtlicher Sorgfaltspflichten von Unternehmen, 2018, pp. 72 ss.

${ }^{23}$ Cfr. MANAcorda, en Manacorda/Marletta/VAnacore (eds.), RIDP, (1), 2017, pp. 56 ss. En Alemania ha sido especialmente discutido el caso Siemens, si bien en el marco de un proceso civil. Ante el LG München se discutía si la empresa tenía que abonar los gastos de una investigación interna debida originada por un caso de corrupción en una de sus filiales. El Tribunal consideró que no contar con un sistema de 
La construcción de la Joint Criminal Enterprise propia del Derecho penal internacional supone una forma relajada de coautoría que a priori podría también ser útil para establecer la responsabilidad del superior. Su fundamento descansa en la existencia de un acuerdo previo entre todos los intervinientes, siendo irrelevante para apreciar la coautoría la presencia en el momento del hecho. Los tribunales internacionales han relajado notablemente los requisitos para admitir la responsabilidad no solo en el plano objetivo, en cuanto que no es necesario ningún dominio del hecho, ni tan siquiera la presencia física en el lugar de ejecución, sino también en el subjetivo, en cuanto que admiten la existencia de responsabilidad para los participantes en el plan común, por cualquier comportamiento que pueda resultar previsible. Por esta razón, al menos en su forma más laxa, esta teoría levanta serías objeciones desde el punto de vista del principio de culpabilidad. No obstante, si sus requisitos se perfilan y se acercan a los que habitualmente tiene la coautoría, plantea similares problemas probatorios a los casos anteriores. ${ }^{24}$

El grupo de casos más importante desde un punto de vista práctico, y también teórico, es el relativo a la complicidad empresarial. ${ }^{25}$ Se trata de aquellos supuestos en los que las empresas suministran bienes o servicios que favorecen la comisión del delito. Este fue el caso que originó los procesos de Nüremberg contra las empresas que suministraron armamentos o el gas Zyklon utilizado en los campos de concentración. Más modernamente todos los países occidentales han tenido casos de ventas de armamento a regímenes dictatoriales. Las escasas condenas existentes como la de los empresarios holandeses Van Anraat y Konwenhoven se han producido en supuestos que responden a esta estructura. El primero de ellos suministró gas mostaza al régimen de Sadam Huseim, que fue utilizado contra los kurdos, mientras que el segundo financió a través de la compra de madera la guerra entre Libia y Sierra Leona, y vendió además armas a la dictadura libia de Charles Taylor ${ }^{26}$ En este grupo entrarían también los supuestos de empresas tecnológicas que han podido suministrar información sensible a gobiernos, que puede ser utilizada para perseguir a opositores políticos.

La responsabilidad a título de cómplice por este tipo de comportamientos ha sido el aspecto más debatido en los últimos años. La importancia de la complicidad en el Derecho penal internacional no es sin embargo exclusiva de los supuestos de responsabilidad empresarial. Desde los tiempos de Nüremberg, la complicidad lejos de tener un carácter subsidiario, como ocurre en el resto del Derecho penal, es la figura central a la hora de atribuir responsabilidades. Dada la gran cantidad de sujetos que interviene en este tipo de casos y dada la irrelevancia que a veces tiene quien ha sido el autor directo, lo importante es la determinación de los diversos sujetos que han cooperado en él. ${ }^{27}$ Dependiendo del grado de aporte al hecho principal, las conductas de cooperación se han clasificado distinguiendo entre aquellas que posibilitan la

cumplimiento eficaz en las filiales supondría la infracción de un deber de diligencia de los administradores de la matriz. No obstante, este deber de diligencia solo se activa cuando las evidencias de corrupción resultan notables, vid. HÜBNER, en KRAJEWSK/SAAGE MAAB (eds.), Die Durchsetzung menschenrechtlicher Sorgfaltspflichten von Unternehmen, 2018, pp. 69 ss.

${ }^{24}$ Cfr. Ambos, Derecho penal internacional económico, 2018, pp. 105 s.; ScHmidt, Crimes of Business in International Law, 2016, pp. 157 ss.

${ }^{25}$ La bibliografía es en este punto inabarcable, vid. especialmente Report of the International Commission of Jurists Expert Legal Panel on Corporate Complicity in International Crimes. 3 volúmenes, 2008.

${ }^{26}$ Sobre estos casos vid. KALECK, en JeßBERGER/KaLECK/SingelnStein (eds.), Wirtschaftsvölkerstrafrecht, 2015, pp. 95 ss.

${ }^{27}$ Cfr. KalECK, en JeßBERger/KaLECK/SingeLnStein (eds.), Wirtschaftsvölkerstrafrecht, 2015, pp. $111 \mathrm{~s}$. 
realización del hecho, de modo tal que sin su realización no hubiera podido realizarse; las que incrementan sus daños, ayudando a que sus efectos sean mayores; y las que lo facilitan, lo que tendría lugar cuando el comportamiento de la empresa hace más fácil el comportamiento de los autores. ${ }^{28}$

Los resultados de este debate muestran la limitada eficacia de la construcción del aiding and abbeting. Existen, en primer término, numerosos problemas probatorios. Aunque se suministren armas a un dictador no siempre es fácil demostrar que ese material fue precisamente el que se utilizó en los ataques contra la población civil. Esta prueba es especialmente compleja cuando se trata de productos de doble uso, como ocurría en el caso del gas Zyklon, que podía utilizarse como un arma letal, pero también como desinfectante. Además, la jurisprudencia suele exigir que la aportación al hecho principal sea substancial, lo que deja fuera las aportaciones que facilitan o incrementan los daños, según la clasificación anterior. En realidad, al igual que ocurre con los casos de financiación del terrorismo o participación en una organización criminal, de muchas contribuciones puede decirse que aumentan la "capacidad mortífera" de una dictadura o de su ejército, pero no que suponen una participación en un determinado hecho. ${ }^{29}$

Vinculado al debate sobre la complicidad se encuentra la cuestión de los comportamientos neutrales. En muchos casos podría afirmarse que un comportamiento de estas características no supone un riesgo jurídicamente desaprobado y, por tanto, aunque haya existido, en el plano causal, una cierta facilitación del hecho, esta no es imputable objetivamente a su autor. Desde los casos de Nüremberg, la jurisprudencia internacional ha dejado claro que, por ejemplo, realizar un préstamo a un gobierno, aun planteándose la posibilidad de que con ello se financien operaciones contrarias a los Derechos humanos, puede ser considerado moralmente reprochable -hoy diríamos contrario a la RSC- pero no es necesariamente delictivo. ${ }^{30} \mathrm{La}$ doctrina mayoritaria vincula, fundamentalmente, la existencia de un comportamiento neutral a un aspecto subjetivo del comportamiento. Solo cuando el autor conoce con seguridad que su aportación va a ser utilizada para la realización del comportamiento delictivo, el comportamiento pierde su carácter neutral. De este modo, nuevamente, las dificultades probatorias unidas al tipo subjetivo vuelven a aparecer. ${ }^{31}$

\footnotetext{
${ }^{28}$ Cfr. Manacorda, en Manacorda/Marletta/Vanacore (eds.), RIDP, (1), 2017, p. 36.

${ }^{29}$ Cfr. Manacorda, en Manacorda/Marletta/VAnacore (eds.), RIDP, (1), 2017, pp. $59 \mathrm{~s}$.

${ }^{30}$ Cfr. AmBos, Derecho penal internacional económico, 2018, pp. 108 ss. Un ejemplo más moderno podía ser el caso Lehemeyer en Alemania, en relación a la construcción de una empresa en Sudan que dio lugar al desplazamiento de miles de personas pertenecientes a determinadas etnias. La fiscalía de Frankfurt investigó la posible complicidad omisiva de los directivos de la empresa que habían prestado asistencia técnica y dirigido la ejecución del proyecto. Los delitos que se le imputaban eran daños y otros delitos contra el medio ambiente. La Fiscalía rechazó finalmente el asunto entendiendo que no existía deber de garantía, analizando si este deber podía desprenderse de las actuales obligaciones en materia de derechos humanos. La obligación de garantía de esta empresa se extiende exclusivamente a aquellos daños que tengan que ver con la calidad de los materiales empleados, pero no con este otro tipo de daños. Aunque no es este lugar para una mayor profundización teórica, este caso, aunque fue planteado dentro de la comisión por omisión, podía también haber sido un buen ejemplo de comportamiento neutral. Vid. SAAGEMAAS, «The Merowe Dam Project- When does the coin flip from legal business activity to criminal behaviour? Reflections on the concept of guarantor's liability in the context of transnational business activities», Criminal Law Forum, (29), (2018), pp. 603 ss.

${ }^{31}$ Para un análisis de los distintos casos en la jurisprudencia internacional y nacional KALECK, en JEßBERGER/KALECK/SINGELNSTEIN (eds.), Wirtschaftsvölkerstrafrecht, 2015, pp. 115 ss.
} 
Mas allá de la cuestión de prueba, el gran debate en torno a la complicidad empresarial se ha producido a la hora de conformar su aspecto subjetivo. En la dogmática del Derecho penal internacional, elaborada por los tribunales penales internacionales, se discute vivamente si el cómplice necesita no solo conocer que la contribución es eficaz para la comisión de un delito, sino si además es necesario que el autor quiera contribuir, es decir, que actúa de propósito o con dolo de primer grado. Al parecer, los preceptos del Tratado de Roma que regulan esta cuestión habrían optado por esta interpretación altamente subjetiva, si bien los tribunales internacionales, en sus últimas decisiones, sobre todo a partir del asunto Furundzija, se inclinan por una línea más objetiva, donde basta con conocer que la contribución es eficaz para la comisión de un delito, siendo suficiente además el dolo eventual. ${ }^{32}$

Si los problemas para obtener un rendimiento práctico del Derecho penal internacional son ya importantes en estos dos primeros supuestos de complicidad empresarial, los dos grupos restantes quedan muy lejos de una posible responsabilidad penal. El tercer grupo de casos se produce cuando las empresas se benefician de las violaciones de Derechos humanos. Un supuesto frecuente es el del banco donde están depositados los fondos que el dictador ha obtenido a través de la corrupción masiva o la actuación de las fuerzas policiales de una dictadura torturando o realizando cualquier otra violación de Derechos humanos, con el fin de facilitar la actividad de la empresa. Las posibilidades de apreciar en estos casos la complicidad con la violación de derechos es lejana. ${ }^{33}$

En esta materia, la discusión se ha centrado además en supuestos de violación protagonizados casi exclusivamente por Estados, sin que hasta el momento se haya reflexionado en aquellos casos en donde la violación procede de la empresa suministradora de bienes o servicios. Es decir, supuestos tan frecuentes como la utilización de trabajo infantil por las empresas proveedoras. Aunque estructuralmente los casos son similares, normativamente no lo son. Las empresas proveedoras son en muchos casos dependientes económicamente y pueden estar sujetas de facto al poder de dirección de la empresa a la cabeza de la cadena de suministros, lo que lógicamente no ocurre en el caso de la criminalidad estatal.

Finalmente, el Derecho penal internacional tampoco aporta soluciones efectivas en relación a la que se ha dado en llamar complicidad silenciosa, ${ }^{34}$ en la cual las empresas están presentes y hacen negocios en países donde existen violaciones masivas de Derechos humanos, como ocurría con las empresas presentes en Sudáfrica durante el Apartheid ${ }^{35}$ o la actuación de Volkswagen en Brasil durante la dictadura. ${ }^{36}$ De nuevo, este caso habría que ubicarlo en exclusiva en el terreno de la moral o la responsabilidad social empresarial, y como mucho sería relevante cuando existe una normativa de embargos económicos $u$ otro tipo de sanciones comerciales.

\footnotetext{
32 Vid. MARZEN, «The Furundzija Judgment And Its Continued Vitality In International Law», Creighton Law Review, (43), 2010, pp. 505 ss.

${ }^{33}$ Cfr. Manacorda, en Manacorda/Marletta/VAnacore (eds.), RIDP, (1), 2017, pp. $52 \mathrm{~s}$.

${ }^{34}$ Cfr. Ambos, Derecho penal internacional económico, 2018, pp. 32 s., 112.

${ }^{35}$ Cfr. KALECK, en JEßBERGER/KALECK/SingELNSTEIN (eds.), Wirtschaftsvölkerstrafrecht, 2015, p. 93, dando cuenta del proceso que se inició, sobre la base de la ATCA, contra varias empresas europeas y americanas por su presencia durante el régimen del Apartheid. La demanda finalmente se desestimó por falta de competencia.

${ }^{36}$ Vid. De Brito Gueiros/De Alencar e Miranda, «Brazilian Report on Individual Liability for Business Involvement in International Crimes», en MANACORDA/MARLETA/VANACORE (eds.), RIDP, (1), 2017, pp. 141 ss.
} 
Los déficits que acaban de señalarse no suponen que haya que dejar al Derecho penal internacional en una suerte de vía muerta. Al contrario, este debe incorporar nuevos desarrollos que le permitan ser más eficaz. ${ }^{37}$ En primer lugar, resulta imprescindible incorporar la responsabilidad penal de las personas jurídicas. ${ }^{38}$ La negativa a admitir la responsabilidad de un colectivo probablemente esté en los genes del Derecho penal internacional. La gran aportación de Nüremberg fue individualizar en personas de carne y hueso las atrocidades del régimen nacionalsocialista, sin permitir que, como había ocurrido hasta ese momento, los autores de estas atrocidades se refugiasen en el Estado. Contravenía probablemente a esta lógica admitir que los dirigentes empresariales responsables pudieran quedar camuflados bajo el nombre de sus empresas. Admitir la responsabilidad del colectivo empresarial, hubiera servido de argumento a los responsables individuales para negar su responsabilidad.

Este planteamiento, aunque comprensible en su momento, debe superarse hoy. Las ventajas de política criminal que se derivan de la responsabilidad penal de las personas jurídicas también deben aprovecharse en el marco del Derecho penal internacional. Las dificultades probatorias que acabamos de enunciar se aligerarían a través del fomento de la cooperación en el proceso penal. La implantación de programas de cumplimiento sería extremadamente útil en este punto, pues lógicamente no se centrarían exclusivamente en evitar comportamientos que puedan ser tachados de genocidio o lesa humanidad, sino que necesariamente deberían de incorporar medidas para controlar por ejemplo la utilidad que se le da a un determinado bien o servicio prestado o habrían de plantearse cuestiones como cuál ha de ser la actuación de la empresa en el marco de dictaduras. Dicho de otro modo, gran parte de lo que hoy se enmarca en la Responsabilidad Social Corporativa pasaría a ser parte del cumplimiento normativo, lo que entraña un grado mayor de enforcement para este tipo de obligaciones.

La evolución del Derecho penal internacional podría también llevar a la inclusión de nuevos core crimes que superen el marco de Nüremberg. En general, los core crimes siguen siendo delitos pensados para el Estado como principal protagonista de las violaciones a los Derechos humanos. El significado político criminal de la discusión en torno a la sujeción de las multinacionales a los Derechos humanos, lo que pone de relieve es la necesidad de establecer una nueva generación de delitos de Derecho penal internacional cuyos actores principales sean las empresas. El delito de ecocidio sería a mi juicio una de estas nuevas figuras. ${ }^{39}$ Igualmente en este marco debe encajarse la propuesta de NAUCKE de un Derecho penal internacional económico, que establezca figuras delictivas que atentan contra bienes jurídicos globales como

\footnotetext{
${ }^{37}$ Vid. p.ej., las «Final Resolutions on Individual Liability for Business Involvement in International Crimes» de la Sección I del XX Congreso de la AIDP, en MANACORDA/Marleta/VANACore (eds.), RIDP, (1), 2017, pp. 75 ss.

${ }^{38}$ A favor, p.ej., Амвos, «International Economic Criminal Law», Criminal Law Forum, (29), 2018, pp. 499 ss.; El MISMO, Derecho penal internacional económico, 2018, pp. 29 ss.; PÉrez CEPEDA, Revista Penal, (44), 2019, pp. 138 s. También ampliamente sobre esta cuestión ScHмidT, Crimes of Business in International Law, 2016, pp. 369 ss.

${ }^{39}$ Vid. NiETo MARTín, «Bases para un futuro Derecho penal internacional del medio ambiente», AFDUAM, (16), 2012, pp. 137 ss.; DE VICENTE, «Hacia un derecho penal medioambiental: catástrofes ambientales y ecocidio», en Demetrio CRESPo/Nieto MARTín, Derecho penal económico y Derechos humanos, 2018, pp. 245 ss. Una propuesta de convención internacional puede verse en NEYERT (dir.), Des écocrimes à l'ecocide. Le droit penal au secours de l'environnement, 2015. Igualmente las distintas intervenciones en el coloquio «Hacia un Derecho penal internacional del medio ambiente: del Pacto Global a la Convención sobre el delito de ecocidio», Madrid, 4 de diciembre de 2019 (http://blog.uclm.es/repmult/).
} 
la estabilidad financiera. ${ }^{40}$ La protección de los Derechos sociales, económicos y culturales que tradicionalmente han estado relegados a un segundo plano por el Derecho penal internacional habría de ser el objetivo prioritario de estas nuevas figuras. ${ }^{41}$

En cualquier caso, debe subrayarse que las obligaciones positivas que tienen las empresas en materia de Derechos humanos (infra 3.1) son de gran importancia para alcanzar una mayor efectividad por parte del Derecho penal internacional. A medida que aumenta la regulación de la organización preventiva empresarial en materia de Derechos humanos, se iluminan las zonas oscuras de la responsabilidad penal que anteriormente se han expuesto. Es lo que ocurre, por ejemplo, en los casos de complicidad en la no evitación de infracciones o el aprovechamiento de infracciones en materia de Derechos humanos. Las obligaciones de diligencia debida hacia los proveedores o hacia las empresas a las que se les suministran determinados bienes abre las puertas de considerar que existe un deber de garantía o conductas de participación omisiva. No realizar la due diligence en relación a un proveedor aumenta al riesgo, por ejemplo, de que en sus actividades aparezca el trabajo infantil. Los límites en los que resulta razonable hablar de acciones neutrales se clarifican igualmente cuando existen normas relativas a productos de doble uso que exigen cerciorarse de cuál será su resultado final.

El cumplimiento normativo en Derechos humanos aumenta significativamente las posibilidades de prueba del elemento subjetivo. Las normas de cumplimiento, como ocurre en materia de corrupción, suelen incidir en la obligación de conocer de los superiores, acompañando esta obligación de deberes de registro documental. Las normas de diligencia debida pueden también tener gran importancia con el fin de establecer en qué medida es legítima una delegación de funciones. Como ponen de manifiesto las recomendaciones de la OCDE en relación a la actuación de las empresas en zonas de gobernanza débil, ${ }^{42}$ los deberes de supervisión de la alta dirección sobre las actividades delegadas se intensifican en aquellas operaciones o actividades que presenten un alto riesgo de violación. ${ }^{43}$

En lo concerniente a las sanciones, el Derecho penal internacional debiera acoger planteamientos procedentes de la justicia restaurativa, cuando no proponer directamente la utilización de mecanismos de justicia restaurativa basados en la diversion. ${ }^{44}$ La pena más común que se impone a la persona jurídica, la multa, para reflejar el enorme desvalor de estos comportamientos requiere tal dureza que puede poner en peligro la supervivencia de una empresa y, sin llegar a tanto, perjudicar los derechos de reparación de las víctimas. Por esta

\footnotetext{
${ }^{40}$ NAUCKE, Der Begriff der politischen Wirtschaftsstraftat. Eine Annäherung, 2012, y los trabajos que repasan su propuesta en JEßBERGER/KALECK/SINGELNSTEIN (eds.), Wirtschaftsvölkerstrafrecht, 2015. Vid. también las reflexiones sobre los delitos internacionales económicos de ARENAL LORA, Crímenes económicos en Derecho internacional: Propuesta de una nueva categoría de crímenes contra la humanidad, 2019; CASTILLO MONTERREY, «El expolio de las riquezas nacionales: un nuevo reto para el Derecho Penal Internacional», en DEMETRIO CRESPO (dir.), Crisis financiera y derecho penal económico, 2014.

${ }^{41}$ Cfr. KALECK, en JEßBERGER/KALECK/SINGELNSTEIN (eds.), Wirtschaftsvölkerstrafrecht, 2015, p. 86.

${ }^{42}$ OECD, Risk Awareness Tool for Multinational Enterprises in Weak Governance Zones, 2006, pp. 21 ss.

${ }^{43}$ Cfr. WitTIG, en JeßBERGER/KALECK/SingELNSTEIN (eds.), Wirtschaftsvölkerstrafrecht, 2015, p. 251.

${ }^{44}$ Las soluciones de justicia restaurativa, como fórmula de reparación, podrían ser implementadas incluso motu propio por las empresas en el marco de lo que los Principios rectores denominan "mecanismos de reclamación no estatales”. En la experiencia comparada un caso de gran interés es el puesto en marcha por la empresa minera brasileña Samarco, tras la catástrofe de Mariana, a través de la creación de un sistema de reparación. Una completa información sobre este plan de reparación puede verse en https://www.fundacaorenova.org/. Igualmente vid. las distintas entrevistas a los responsables del sistema de reparación en http://blog.uclm.es/repmult/.
} 
razón, y tal como he propuesto en otro lugar, cabría poner en marcha un nuevo tipo de sanciones al que he denominado "sanciones empoderativas". Su objetivo sería quitar poder a los dirigentes empresariales y dárselo a las víctimas. La equity fine, cuya formulación data de los primeros años ochenta del pasado siglo, se ha incorporado recientemente a la legislación australiana y resulta un modelo a seguir. La comisión de un delito implica una reducción del valor de cada acción, con el que a la vez se crea un nuevo paquete de acciones que se pone en manos de las víctimas. La reincidencia de la empresa disminuye el valor de las acciones originarias y va dando paulatinamente mayor poder a las víctimas. También podría pensarse en un nuevo tipo de sanciones estructurales que incorporaran sus intereses. Por ejemplo, la pena de intervención sería propicia para que al lado de un interventor público se otorgasen también de algún modo poder a las comunidades afectadas por la infracción. ${ }^{45}$

\section{El Derecho penal económico europeo de los Derechos humanos}

Mientras que el Derecho penal internacional se ocupa y debe seguir haciéndolo de las violaciones más importantes a los Derechos humanos, la creación de una nueva rama del Derecho penal económico, centrada en la protección de los Derechos humanos, tendría como finalidad sancionar la violación de normas estatales o supranacionales cuya función es regular la actividad empresarial con el fin de evitar la violación de Derechos humanos. Esta nueva regulación pública, todavía en ciernes, genera bienes jurídicos merecedores de protección penal, como la transparencia relativa a aspectos no financieros o la regulación preventiva de la empresa. Se trata de bienes jurídicos intermedios o instrumentales ${ }^{46}$ característicos del Derecho penal económico, cuya función última es servir a la protección de los Derechos humanos.

En lo que sigue analizaremos, en primer lugar, la aparición de la normativa estatal, europea y supranacional destinada a regular el comportamiento de las empresas en materias de Derechos humanos. Como ocurre normalmente, el Derecho penal económico también tiene en esta materia un marcado carácter accesorio por lo que solo podrá desarrollarse en la medida en que exista una regulación extrapenal que vaya conformando el contenido de los nuevos deberes empresariales. En la segunda parte de este apartado se esbozarán las figuras delictivas, que pueden conformar este nuevo sector del Derecho penal económico.

\subsection{La protección de los Derechos humanos como objeto de la regulación de la actividad empresarial}

El nacimiento la normativa estatal y supra estatal a la que venimos haciendo referencia es expresión de la reconfiguración de las relaciones entre empresas multinacionales y Derechos humanos. Aunque el Derecho internacional no acaba de situar a las empresas multinacionales al mismo nivel que los Estados a la hora de respetar, proteger y reparar los Derecho humanos, no puede decirse que la situación no se haya modificado. ${ }^{47}$ En las últimas dos décadas hemos

\footnotetext{
${ }^{45}$ Cfr. Nieto MARTín, «Empresas, víctimas y sanciones restaurativas: ¿cómo configurar un sistema de sanciones para personas jurídicas pensando en sus víctimas?», en DE HoYOS SANCHO (coord.), La víctima del delito y las últimas regulaciones procesales penales, 2017, pp. 315 ss.

${ }^{46}$ Cfr. Martínez-Bujan PÉrez, Derecho penal económico y de la empresa. Parte General, 5a ed., 2016, pp. 159 ss.

${ }^{47}$ Para un resumen de la situación GuAMÁn HERnÁNDEZ/Moreno GonZÁLEZ, Empresas multinacionales y Derechos Humanos, 2018.
} 
asistido a un cambio substancial, que ha supuesto un transvase paulatino de contenidos entre la Responsabilidad Social Corporativa y el hard law o, al menos, una interacción entre ambos sectores.

En el Derecho internacional de los Derechos humanos se lleva años discutiendo cuáles son las obligaciones de las empresas multinacionales. Las posiciones más avanzadas proponen crear un tratado, el denominado instrumento vinculante, que declare que estas están obligadas por los Derechos humanos de manera semejante a los Estados, en cuanto que su poder y capacidad para afectarlos es similar. Esta pretensión implica que las empresas no solo tendrían la obligación negativa, como cualquier persona, de no afectarlos negativamente (respetar), lo que incluye también los denominados efectos horizontales, sino que también estarían obligadas positivamente a prevenir cualquier tipo de afectación en el marco de su actividad (proteger), lo que implica evitar comportamientos lesivos para los Derechos humanos de todos los que están bajo su dominio, y a reparar (remediar) los efectos de sus comportamientos. En la actualidad existe una Resolución de la Asamblea General de Naciones Unidas que insta a la creación de un instrumento vinculante y existe un grupo de trabajo específico, mas de momento no se esperan avances decisivos en este sentido. ${ }^{48}$ En el extremo opuesto a la opción de la vinculatoriedad, se encuentra la opción voluntarista. La vinculación positiva de las empresas con los Derechos humanos debe situarse en el plano de la responsabilidad social corporativa. Esta opción se plasma en el Pacto Global y procede de los años setenta del pasado siglo con las Directrices de la OCDE para empresas multinacionales. ${ }^{49}$

La forma más exacta de describir la posición actual sería indicar que se encuentra en un punto medio entre ambos extremos, que está representado por los Principios rectores de Naciones Unidas para empresas multinacionales, aprobados por el Consejo de Derechos humanos en el $2011 .{ }^{50}$ Los Principios constituyen un instrumento de soft law, en cuanto que se trata de recomendaciones no vinculantes, mas como es conocido en el Derecho internacional hoy las barreras entre el Derecho duro y el blando se han ido diluyendo. Muchos instrumentos de soft law tienen más eficacia y repercusión que convenios internacionales. La eficacia de las normas de Derecho internacional hoy se fundamenta en buena medida en la existencia de una red de apoyos que se prestan entre las diversas organizaciones globales (Estados, organizaciones internacionales, empresas, etc.). ${ }^{51}$ La OCDE ha acomodado sus Directrices, otra norma de soft law, a los principios. Igual ha pasado en el marco de la estandarización privada con la norma ISO 26000 sobre responsabilidad social corporativa. ${ }^{52}$ Los Principios rectores han impulsado

\footnotetext{
${ }^{48}$ Vid. con referencias, PÉrez CePeda, Revista Penal, (44), 2019, pp. 136 s.

${ }^{49}$ Para ver toda la evolución, vid. solamente FORCADA BARONA, «Derecho internacional, responsabilidad social corporativa y derechos humanos», en Demetrio CRESPo/Nieto MARTín (dirs.), Derecho penal económico y Derechos humanos, 2018, pp. 53 ss. No se tiene en cuenta en este lugar una vía alternativa que es la que representan los acuerdos de inversión, desde la óptica penal vid. PÉREZ CEPEDA, «Acuerdos de libre comercio y el sistema internacional de Derechos Humanos en el marco del Derecho penal internacional», en De la Cuesta et al. (dirs.), Liber amicorum. Estudios jurídicos en homenaje al Prof. Dr. h. c. mult. Juan Terradillos Basoco, 2018, p. 617.

${ }^{50}$ Informe del Representante Especial del Secretario General para la cuestión de los Derechos humanos y las empresas transnacionales, Principios Rectores sobre las empresas y los Derechos humanos, 2011.

${ }^{51}$ Cfr. NiETo Martín, «Transformaciones del ius puniendi en el Derecho global», en Nieto MARTín/García MoReno (dirs.), Ius puniendi y global law. Hacia un Derecho penal sin Estado, 2019, pp. 49 ss.

${ }^{52}$ Vid. UNE-ISO 26000, Guía de Responsabilidad Social, 2010, especialmente los apartados 6.3.3 (diligencia debida en derechos humanos), 6.3.4 (riesgos en derechos humanos), 6.3 .5 (evitar la complicidad).
} 
también la acción de la UE, primero a través de la "Estrategia renovada de la UE para 2011-2014 sobre la responsabilidad social de las empresas" y el Plan de Acción de la UE para los Derechos humanos y la Democracia aprobado en 2015. ${ }^{53}$ Fruto de este Plan, los Estados miembros han de aprobar sus Planes Nacionales en materia de Derechos humanos, que lógicamente tienen en cuanta los Principios ONU. ${ }^{54}$ A partir de este tipo de estándares y normas de soft law, algunos ordenamientos nacionales y la propia UE han empezado a gestar una regulación económica de la actividad empresarial, esto es, auténtico hard law, que interactúa reforzando las normas procedentes de la RSC.

El eje sobre el que descansan los principios es que, como por otra parte es evidente, los Estados son los principales responsables del respeto a los Derechos humanos. Esta obligación les exige precisamente garantizar que las empresas nacionales que se sitúan bajo su control respeten los Derechos humanos, lo que exige la adopción de medidas legislativas, que incluyen el recurso al Derecho penal. Estas medidas legales en que debe concretarse la acción de los Estados tienen varios frentes: el acceso a la justicia de las víctimas, propiciar la reparación, etc. Sin embargo, el que más nos interesa es la denominada due diligence empresarial con el fin de evitar la violación de Derechos humanos.

No obstante, antes de analizar las medidas que al hilo de esta obligación se han ido produciendo en los últimos años, examinaremos uno de los ejes centrales de los Principios, la denominada due diligence en Derechos humanos. ${ }^{55}$

\section{a. Cumplimiento normativo en Derechos humanos}

En efecto, uno de los aspectos que con más detalle se abordan en los Principios es el relativo al contenido de las obligaciones de diligencia debida que las empresas deben adoptar con el fin de evitar que su actuación tenga efectos negativos sobre los Derechos humanos. Los Principios no hablan en ningún momento de la adopción de programas de cumplimiento en esta materia, sino que utilizan el término de due diligence. Sin embargo, para quien esté acostumbrado a la estructura y metodología de los planes de cumplimiento es fácil advertir que los contenidos y la metodología son idénticos. Los Principios inauguran por ello un nuevo ámbito del cumplimiento normativo, el relativo a los Derechos humanos, ${ }^{56}$ cuya regulación básica se encontraría en los Principios 15 a 24. Por esta razón, a partir de ahora, las empresas además de

${ }^{53}$ Vid. https://ec.europa.eu/anti-trafficking/eu-policy/action-plan-human-rights-and-democracy-20152019_en.

${ }^{54}$ Sobre el Plan español y otras medidas europeas, Pérez CEPEDA, Revista Penal, (44), 2019, pp. 134 ss.

${ }^{55}$ Vid. ZÚNínA RODRíGUEZ., «Responsabilidad penal de las personas jurídicas y derechos humanos. Una valoración desde la reforma de 2015 de la legislación española», en DemETRIo CRESPO/NieTo MARTín (dirs.), Derecho penal económico y Derechos humanos, 2018, pp. 99 ss.

${ }^{56}$ Sobre este incipiente cumplimiento normativo en Derechos humanos, vid. p.ej., РіEтH, «Corporate compliance and Human Rights», Criminal Law Forum, (29), 2018, pp. 595 ss.; BuSEKIST/DImISC, «Compliance als Instrument der Menschenrechtsshutzes», en Krajewski/Oenm/SAage-MaAß (eds.), Zivil- und Strafrechtliche Unternehmensverantwortung für Menchenrechtsverletzungen, 2018, pp. 267 ss., quienes acertadamente señalan las vinculaciones entre RSC y cumplimiento normativo (Corporate Social Responsability Compliance). Para indagar los orígenes de la obligación de diligencia que incorporan los principios y observar, p.ej., cómo se invocan, entre otras muchas, las obligaciones en materia de blanqueo es revelador De SchutTer/RAmasastry/TAYlor/Thompson, Human Rights Due Diligence: The Role Of States, 2012. 
incluir materias como la corrupción, el Derecho de la competencia, el blanqueo de capitales, etc., deben incluir expresamente una política en materia de Derechos humanos.

La inclusión de las obligaciones de las empresas en materia de Derechos humanos en el cumplimiento normativo consigue darles una mayor efectividad. Esencialmente porque, de un lado, los dota de una mayor fuerza vinculante de "puertas para adentro" que no siempre está presente en la Responsabilidad Social Corporativa. Los planes de cumplimiento normativo exigen, por ejemplo, que sus violaciones sean investigadas y sancionadas disciplinariamente o la necesidad de canales de denuncia. Pero también, de otro lado, la conceptualización de la due diligence como cumplimiento normativo ayuda a entender que su papel es también la reducción de riesgos legales por parte de las empresas vinculados a la violación de Derechos humanos. En este sentido, destacan procedimientos exigiendo responsabilidad civil, ${ }^{57}$ pero también lógicamente procedimientos penales. El que las normas de soft law, procedentes en gran medida de la Responsabilidad Social Corporativa, se conviertan en estándares de cuidado aplicables en la responsabilidad civil ${ }^{58} \mathrm{o}$, en su caso, la responsabilidad penal, es una muestra más de la tenue, cuando no inexistente, barrera que separa hoy al soft y al hard law.

Mas también, como vamos a ver, para el cumplimiento normativo, resulta muy provechoso el acercamiento al campo de la RSC. La carga genética más importante de los planes de cumplimiento al día de hoy es el control interno, lo que ha implicado asumir fundamentalmente su metodología. La due diligence tal como la establecen los Principios tiene, no obstante, elementos muy importantes de la Responsabilidad Social Corporativa, que se traducen, por ejemplo, en la forma de efectuar el análisis de riesgos. Esta fusión de elementos provenientes del control interno y de la Responsabilidad Social Corporativa que caracteriza el cumplimiento en Derechos humanos abre vías de evolución muy interesantes.

Los Principios insisten en los siguientes puntos, que son vitales dentro de cualquier programa de cumplimiento. En primer lugar, un compromiso político de la dirección de la empresa (Principio 16), que exprese su compromiso con los Derechos humanos y que indique lo que se espera de cada uno de los empleados, pero también de aquellos que se relacionan con ella. Este compromiso debe ser público, y debe quedar reflejado en los distintos procedimientos de la entidad. Además, debe ser necesariamente divulgado, debiendo realizarse también acciones formativas. En segundo lugar, los Principios se detienen en el epicentro de todo programa de cumplimiento: el análisis de riesgos (Principio 17). La empresa debe evaluar el impacto real y potencial de las actividades sobre los Derechos humanos, para lo que debe recurrir a expertos

\footnotetext{
${ }^{57}$ Vid. REQUEJO IsIDRO, Violaciones graves de derechos humanos y responsabilidad civil, 2009; una panorámica actual, centrada en los problemas de competencia, en ÁlVAREZ ToRnÉ, «Tendencias actuales en materia de responsabilidad civil internacional por vulneraciones de derechos humanos cometidas por empresas», REDI, (67), 2015, pp. 291 ss. Para una visión más material, vinculando precisamente las obligaciones de diligencia debida o la realización del programa de cumplimiento como criterio determinante para establecer la culpa en la responsabilidad civil vid. HüBnER, en KraJEWSK/SAAge MAAB (eds.), Die Durchsetzung menschenrechtlicher Sorgfaltspflichten von Unternehmen, 2018, pp. 61 ss.

${ }^{58}$ En este punto el caso probablemente más conocido es la decisión de la Corte Superior de Ontario, Choc v. Hudbay Minerals, donde se estableció que la sociedad matriz canadiense tenía un deber de cuidado en relación a los ciudadanos de Guatemala afectados por la actividad de una de sus filiales. Para ello, el tribunal tuvo en cuenta que la empresa Hudbay había adoptado en sus Voluntary Principles on Security and Human Rights “a detailed set of standards aplicable to the use of private security forces at resource extractive projects", vid. Choc v. Hudbay Minerals Inct et al., 2013 ONSC 998 (CanLII) www.canlii.ca/t/fwtbt.
} 
independientes e internos, y consultar con las partes potencialmente afectadas. Este análisis debe realizarse antes de emprender cualquier clase de actividad empresarial.

La due diligence diseñada en los Principios, tal como antes se indicó, aporta además criterios muy interesantes para el desarrollo futuro de los programas de cumplimiento. En este sentido, destacaría en primer lugar que se trata de un cumplimiento orientado a las víctimas. Como consecuencia de su conexión con el control interno, la evaluación de riesgos que realiza la empresa, en el marco del cumplimiento normativo usual, se focaliza exclusivamente en los riesgos que la realización de una actividad ilícita puede acarrear para el buen funcionamiento y la consecución de los objetivos, principalmente económicos, de la empresa. Por el contrario, en materia de Derechos humanos la evaluación de riesgos se hace desde una perspectiva social. Lo importante para determinar cuándo un daño debe ser prevenido son sus efectos sobre las potenciales víctimas. ${ }^{59}$ Hay por ello un intercambio muy interesante entre los papeles de víctimas y stakeholders procedentes de los análisis de Responsabilidad Social Corporativa. ${ }^{60}$ Coherentemente con este punto de partida, el cumplimiento en materia de Derechos humanos es también reparador, por lo que debe contener los protocolos oportunos de atención y reparación a las víctimas. ${ }^{61}$ Esta última cuestión debe tenerse muy en cuenta a la hora de diseñar un sistema penal de responsabilidad penal de personas jurídicas en materia de Derechos humanos y entronca con la propuesta que antes se efectuaba de una nueva generación de sanciones reparadoras/empoderadoras.

Existen otros rasgos peculiares del cumplimiento normativo en Derechos humanos, que insisto deberían trasladarse al cumplimiento general. Así se trata de un cumplimiento participativo y en el que necesariamente han de intervenir expertos independientes. Los Principios exigen que en el análisis de riesgos, además de consultarse a los posibles afectados (los stakeholders en el lenguaje de la Responsabilidad Social Corporativa), deban participar expertos independientes (Principio 18). Pero el rasgo, sin duda más llamativo, es que incluye no solo el control sobre los trabajadores de la entidad, sino que pone el acento en la responsabilidad de la empresa para evitar que terceros que se relacionan con ella y que están bajo su control afecten a los Derechos humanos (Principio 17). Quizás por ello incluso se emplea el término due diligence que en la práctica empresarial siempre se ha referido a examinar el cumplimiento de terceras personas, como por ejemplo ocurre en materia de corrupción o en blanqueo de capitales.

Este cumplimiento normativo de terceros constituye, sin duda, el aspecto esencial y más característico del cumplimiento en Derechos humanos. Como antes se ha expuesto al analizar los diversos casos de Derecho penal internacional, las multinacionales no siempre afectan directamente como personas jurídicas los Derechos humanos, sino que lo hacen terceros

\footnotetext{
${ }^{59}$ En el comentario al Principio 17 se señala con gran claridad: "la debida diligencia en materia de Derechos humanos puede integrarse en los sistemas más amplios de gestión de riesgos de la empresa, a condición de que no se limiten a identificar y gestionar riesgos importantes para la propia empresa, sino que incluyan los riesgos para los titulares de derechos”, Principios (n. 5), p. 21. Cfr. BuseKIst/Dimisc, en Krajewsisi/Oehm/SAAge-MAAß (eds.), Zivil- und Strafrechtliche Unternehmensverantwortung für Menchenrechtsverletzungen, 2018, p. 273.

${ }^{60}$ Como ya han puesto de manifiesto los primeros estudios de victimología corporativa, vid. SAAD DINIZ, Victimología corporativa, 2019.

${ }^{61}$ Lo que entronca con experiencias como las de Samarco, citadas en n. 45. Las grandes empresas multinacionales dentro de sus programas de cumplimiento debieran por ello prever, p.ej., la necesidad de realizar reparaciones inspiradas en los principios de justicia restaurativa. Vid. ya una orientación similar en SAAD DinIZ, Victimología corporativa, 2019, pp. 190 ss.
} 
relacionados con ellas. En primer lugar, sus filiales, pero en segundo lugar y sobre todo los proveedores, dentro de la denominada cadena de valor, que se ha globalizado y en la que la empresa multinacional ocupa una posición preminente. La inclusión de las filiales y, sobre todo de la cadena de aprovisionamiento, cambia los contornos de los planes de cumplimiento habituales. En efecto, desde hace tiempo en el marco del cumplimiento normativo lo normal era considerarlo una política corporativa, común a todo el grupo, ${ }^{62}$ pero el cumplimiento de proveedores o de terceros, salvo en casos puntuales como la corrupción, ${ }^{63}$ estaba mucho menos desarrollado. Para el cumplimiento en Derechos humanos la idea que delimita el perímetro del cumplimiento normativo no es la persona jurídica, sino las posibilidades de controlar el comportamiento de terceros, que en el caso de los proveedores puede derivarse de situaciones de dependencia económica.

La OCDE ha ido publicando en los últimos años una serie de Guías de carácter sectorial en las que va concretando en qué consisten las obligaciones de cumplimiento en el seno de la cadena de suministro. Un principio esencial, dentro de estas Guías, es el de "conoce a tu proveedor", que implica conocer la totalidad de la cadena y los riesgos existentes, con el fin de desarrollar medidas de control en atención a la intensidad del riesgo. ${ }^{64} \mathrm{~A}$ partir de este análisis de riesgos, las medidas de control pueden consistir en actividades de supervisión del proveedor a través de visitas de inspección, la formación de sus empleados y directivos, la puesta a disposición de canales de denuncia de la empresa, etc. La base jurídica de estas medidas de supervisión es contractual. La empresa con capacidad de control sobre los proveedores debe incluir estas facultades de supervisión como parte de los contratos. Llegado el caso, su incumplimiento puede dar lugar a la rescisión.

Igualmente, al lado de los poderes de supervisión de la propia empresa otro medio de control es recurrir a auditores independientes, que en nombre de la empresa examinen las condiciones de un determinado proveedor. La técnica de la auditoria es esencial, por ejemplo, en el Reglamento (UE) 2017/81 sobre minerales en zonas de conflicto, que obliga a los importadores a realizar auditorías externas e independientes sobre sus proveedores ${ }^{65} \mathrm{La}$ otra técnica sería la certificación, que puede ser útil donde el control es menor. Se exigiría, por ejemplo, solo tener proveedores, dentro de toda la cadena debidamente certificados. ${ }^{66}$

\footnotetext{
${ }^{62}$ Vid. Nieto Martín, en Nieto Martín (dir.), Manual de cumplimiento penal en la empresa, 2013, pp. 104 ss. ${ }^{63}$ Vid. Nieto Martín, en Nieto MarTín (dir.), Manual de cumplimiento penal en la empresa, 2013, pp. 357 ss., como es conocido en materia de corrupción la due diligence se efectúa para asegurase de la honorabilidad de socios de negocios o consultores, abogados, etc., que van a realizar en nombre de la empresa gestiones ante las autoridades públicas extranjeras.

${ }^{64}$ Las directrices publicadas hasta ahora por la OECD en relación a las cadenas de suministro son las siguientes: OECD Due Diligence Guidance for Responsible Supply Chains of Minerals from Conflict-Affected and High-Risk Areas, 3 ed. 2016; OECD-FAO Guidance for Responsible Agricultural Supply Chains; OECD, Due Diligence Guidance for Meaningful Stakeholder Engagement in the Extractive Sector; OECD, Due Diligence for Responsible Corporate Lending and Securities Underwriting; OECD Due Diligence Guidance for Responsible Supply Chains in the Garment and Footwear Sector.

${ }^{65}$ Vid. p.ej., la OECD-FAO Guidance for Responsible Agricultural Supply Chains, pp. 38 s.

${ }^{66}$ No obstante, la técnica de la certificación se utiliza mucho más con la finalidad de que la empresa líder de la cadena controle la calidad de los productos de los distintos proveedores. La certificación con ello se ha convertido en una forma de regulación global de carácter privado de la que pueden derivarse también efectos perjudiciales para los Derechos humanos, vid. al respecto NiETo MARTíN, «La responsabilidad penal de empresas multinacionales y la seguridad alimentaria», en DeMETRIo CRESPO/NieTO MARTin, Derecho penal económico y Derechos humanos, 2018, pp. 283 ss.
} 
Como puede apreciarse, sea cual sea la técnica que se emplee, el cumplimiento normativo en materia de Derechos humanos implica nuevamente una privatización de funciones públicas, con el fin de suplir las carencias, por ejemplo, de los sistemas de inspección de trabajo, medioambientales o sanitarios en muchos países. Son las empresas, los auditores o las certificadoras quienes suplen a los servicios de inspección estatales, en base a una relación no basada en el Derecho público, sino totalmente contractual. La obligación de someterse a los servicios de inspección de la empresa, a auditorias independientes o exigir certificaciones debe establecerse contractualmente con los distintos proveedores.

Existe aún una característica ulterior del cumplimiento normativo en materia de Derechos humanos: está sometido a la obligación de transparencia e incluso al control de una entidad pública. Los Principios dejan en manos de los Estados cómo asegurar que las empresas cumplan con sus obligaciones, en este punto se menciona lógicamente la posibilidad de utilizar el Derecho penal. No obstante, como listón mínimo los Principios apuestan por un cumplimiento a través de la transparencia. Ello supone una confianza en el mercado y en la existencia de consideraciones éticas en los inversores. ${ }^{67}$ La lógica es que los mercados, los consumidores y los inversores fundamentalmente, sabrán premiar o castigar mediante sus decisiones a las empresas más diligentes. En cualquier caso, los Principios requieren de los Estados que obliguen a las empresas, cuyas operaciones o contextos operacionales impliquen graves riesgos de imparto sobre los Derechos humanos a informar oficialmente de las medidas que toman al respecto. Esta obligación debe hacerse con la frecuencia y en la forma necesaria para que exista una información suficiente acerca de los riesgos que entrañan sus comportamientos, como también para valorar si su respuesta ha sido la adecuada. ${ }^{68}$

\section{b. La respuesta en los ordenamientos nacionales}

Algunos legisladores nacionales están tomando medidas para la protección de los Derechos humanos que están directamente influidas por los Principios y que responden a la estrategia de autorregulación más transparencia que acabamos de comentar. ${ }^{69}$ Mientras alguna de estas iniciativas tiene carácter global -afectan a la totalidad de los derechos, incluyendo también, el medio ambiente o las medidas anticorrupción- otras se enfocan en la cadena de proveedores y sobre todo en la utilización de trabajo forzado.

Entre los países de la UE, el país que ha adoptado una legislación más novedosa ha sido Francia, a través de la denominada Ley de vigilancia empresarial, que afecta a las empresas de más de 5000 trabajadores. Estas tienen la obligación de contar con un plan de vigilancia. La concreción del plan de vigilancia que efectúa la ley muestra su similitud total con los planes de cumplimiento normativo. Este plan tiene los mismos elementos que los programas de

\footnotetext{
${ }^{67}$ Cfr. HoRST, «Shareholder Activism for Human Rights? Aktienrechtliche Instrumente zur mittelbaren Duchsetzung von Menschenrechtspflichte auf den Finanzmärken», en KRAJEWSKI/SAAGE-MAAß (eds.), Die Durchsetzung menschenrechtlicher Sorgfaltspflichten von Unternehmen, 2018, pp. 203 ss.; en general, sobre la eficacia de la transparencia de la RSC vid. HESS, «Social reporting and new gobernance regulation: the prospects of achieving corporate accountability through transparency», Businness Ethics Quartely, (3), 2007, pp. 453 ss.

${ }^{68}$ Vid. comentario al Principio $\mathrm{n}^{\circ} 3$.

${ }^{69}$ Una visión de estas medidas puede encontrarse en GuAMÁn HERnÁNDEZ/Moreno GonZÁLEZ, Empresas multinacionales y Derechos Humanos, 2018, pp. 139 ss.
} 
conformidad que en materia de anticorrupción exige la loi sapen. ${ }^{70} \mathrm{La}$ norma establecía sanciones contra las empresas -de hasta diez millones de euros- que no contaran con plan de vigilancia o tuvieran uno deficientemente implantado. Esta sanción administrativa ha sido, sin embargo, declarada inconstitucional por el Consejo constitucional francés. ${ }^{71}$ En cualquier caso, la positivización del deber de vigilancia y las obligaciones que de él se desprenden para las empresas en materia de Derechos humanos puede dar lugar a reclamaciones civiles ante la justicia francesa por parte de las víctimas.

No existen demasiadas normas similares a la francesa con vocación de abordar el problema globalmente. ${ }^{72}$ Hasta ahora lo que predomina en la legislación nacional son normas sectoriales que especialmente se han centrado en el problema de la esclavitud y la trata de personas. ${ }^{73} \mathrm{La}$ California Transparency in Supply Chains Act de 2010 es probablemente el texto más conocido. ${ }^{74}$ Esta norma no exige a las empresas que establezcan controles determinados con el fin de evitar la esclavitud y el tráfico de personas en sus cadenas de suministros. Se trata de una disclousure act, basta con que la empresa indique o no si se adoptan una serie de controles que de modo indicativo establece la ley. En la parte de ejecución, la Transparency in Supply Chains Act establece también la posibilidad de que la Fiscalía General de California actúe con el fin de comprobar si las empresas cumplen o no sus obligaciones de publicidad y que las empresas le envíen información periódicamente.

La principal característica de esta ley es que hace una serie de preguntas muy concisas acerca de las medidas que las empresas deben adoptar y del modo en que se ha de publicar la información en la página web de la empresa. Las preguntas que las empresas deben responder, además de incrementar la transparencia, persiguen orientar acerca de cuál es el camino que la empresa debe seguir en sus prácticas de cumplimiento normativo. La Supply Chain Act no impone, pero exige a las empresas que informen acerca de si tienen medidas como: (a) la existencia de una verificación externa para la evaluación de los riesgos en la cadena de proveedores, debiéndose describir, en su caso, el procedimiento que utiliza para analizar el riesgo y los criterios que emplea para seleccionar proveedores en función del riesgo; (b) la realización de inspecciones no anunciadas y realizadas por personas independientes en los

\footnotetext{
${ }^{70}$ En concreto el art. L. 225-102-4 del Código de Comercio, indica que el plan contendrá las medidas siguientes: $1^{\circ}$ Un mapa de riesgos para identificar, analizar y priorizar los riesgos; $2^{\circ}$ Procedimientos de evaluación periódica de la situación de las filiales, subcontratistas o proveedores con los que se mantiene una relación comercial establecida, en relación con la cartografía de riesgos; $3^{\circ}$ Acciones apropiadas para mitigar riesgos o prevenir daños graves; $4^{\circ}$ Un mecanismo de alerta y recogida de informes relativos a la existencia o ocurrencia de riesgos, establecido en consulta con las organizaciones sindicales representativas de dicha empresa; $5^{\circ}$ Un sistema de seguimiento de las medidas aplicadas y de evaluación de su eficacia.

${ }^{71}$ Conseil Constitutionnel, $\mathrm{n}^{\mathrm{o}}$ 2017-750 DC, de 23 de marzo de 2017.

${ }^{72}$ En Alemania existen dos informes no oficiales que, a semejanza de la ley francesa, pretenden positivizar el cumplimiento normativo en materia de Derechos humanos. Ambos incluyen un proyecto de ley en esta materia que es de gran interés, vid. KlingER/KrajEWSKi/KreBS/HARTMANN, Verankerung menschenrechtlicher Sorgfaltspflichten von Unternehmen in deutschen Recht, 2016; SCHEPER/GRABOSCH, Die menschenrechtliche Sorgfaltspflicht von Unternehemen, 2015.

${ }^{73}$ En este punto vid. MongiLlo, «Forced Labour e sfruttamento lavorativo nella catena di fornitura dell'imprese: strategie global di prevenzione e reppresione», Revista trimestrale di Diritto penale dell'economia, (3-4), 2019, pp. 630 ss., GARCía SEDANo, Una aproximación desde el Derecho internacional y el Derecho comparado a la regulación de las cadenas de suministro y las formas contemporáneas de esclavitud (en prensa).

${ }^{74}$ Para una información básica, The California Transparency in Supply Chains Act A Resource Guide (https://oag.ca.gov/sites/all/files/agweb/pdfs/sb657/resource-guide.pdf).
} 
locales de los proveedores, con el fin de comprobar si están libres de tráfico de personas y de trabajos forzados; (c) la exigencia de certificación a sus proveedores directos que atestigua que los materiales que utilizan proceden de empresas sin trabajos forzados o trata; (d) la existencia de controles internos, indicando quienes son sus responsables, las sanciones que aplica, la formación que se imparte.

La norma californiana ha servido de inspiración a otras en Australia y en el Reino Unido, también relativas a la trata de personas y a los trabajos forzados. ${ }^{75}$ La Modern Slavery Act en el Reino Unido obliga a las empresas que tengan unos beneficios de al menos 36 millones de libras esterlinas a publicar anualmente, en un lugar destacado de su página web, un informe en el que se indiquen los pasos que han tomado para evitar la esclavitud y el tráfico de personas, en sus negocios y dentro de su cadena de suministro. La ley tiene una vocación universal, y en ello recuerda a la Bribery Act, pues no solo obliga a empresas con sede social en el Reino Unido, sino a todas aquellas que proporcionen bienes o servicios.

\section{c. La regulación europea del comportamiento empresarial en materia de Derechos humanos}

La Unión Europea, que como vimos apoyó los Principios rectores de Naciones Unidas, en el marco de su política sobre Responsabilidad Social Corporativa ha aprobado una serie de textos que muestran el camino a seguir en una futura regulación europea del comportamiento empresarial relativo a los Derechos humanos.

La norma más conocida e importante de la UE es sin duda la Directiva 2014/95 sobre publicación de estados no financieros que enlaza con la idea de un cumplimiento normativo transparente y, por tanto, la idea de mercados y consumidores vigilantes. ${ }^{76}$ Adoptada sobre la base del art. 50.1 TFUE, al igual que el resto de la normativa en materia de sociedades, la Directiva obliga a las empresas de más de 500 trabajadores a que publiquen sus programas de cumplimiento "como mínimo" en materia de medio ambiente, Derechos humanos, lucha contra la corrupción y Derechos de los trabajadores. La publicación debe hacerse dentro del informe de gestión, un documento que acompaña a las cuentas anuales. La información debe incluir la descripción de los riesgos y de las políticas que aplica la empresa y sus resultados. Tal como ha aclarado la Comisión, esta información debe considerarse "información significativa”, es decir, "información cuya omisión o comunicación errónea se considere razonablemente que pudiera influir en decisiones que los usuarios adopten basándose en los estados financieros de la empresa" ${ }^{77}$ Igualmente debe ser fiel, equilibrada y comprensible, lo que implica que "los usuarios de la información no deben verse inducidos a error por inexactitudes significativas,

\footnotetext{
${ }^{75}$ Para una comparación entre ambas, Business AND Humann Rights Resource Center, Modern Slavery in Company Operations and Supply Chains, Madantory Transparence, Mandatory Due Diligence and Public Procurement, 2017.

76 Cfr. EICKENJÄGER, «Die Durchsetzung von Menschenrechten gegenüber Unternehmen mittels nichtfinanzieller Berichterstattung», en KRAJEWSKI/SAAGE-MAAß (eds.), Die Durchsetzung menschenrechtlicher Sorgfaltspflichten von Unternehmen, 2018, pp. 243 ss. Para un estudio de la directiva y su transposición al Derecho español pueden consultarse las distintas intervenciones del Seminario de Información no Financiera: Empresas Multinacionales y Derechos Humanos, Madrid 26 de octubre de 2018 (http://blog.uclm.es/repmult/multimedia/).

${ }^{77}$ Directrices sobre la presentación de informes no financieros (Metodología para la presentación de información no financiera, DO, 2017, C 215/01, p. 5).
} 
por la omisión de información significativa o por la divulgación de información poco significativa". ${ }^{78}$

Existe una gran uniformidad en la forma en que las empresas realizan sus reportes en materia de Derechos humanos. ${ }^{79}$ Los denominados estándares GRI son los más habituales (Global Raporting Initiative). Existen criterios de reporte en materia de evaluación de riesgos y gestión de riesgos (GRI 103), en Derechos humanos (GRI 412), trabajo infantil (GRI 408), trabajos forzados (GRI 409) y anticorrupción (GRI 205). Esta información, aunque en ocasiones se queda en aspectos muy generales, requiere en otros casos una información mucho más detallada, como el número de empleados que han recibido formación, las horas que han dedicado o las operaciones que se han sometido a evaluación de riesgos. La UE ha publicado también su propio modelo de reporte, en donde subraya la necesidad de que esta información comprenda los procedimientos de diligencia debida en su cadena de suministro y la necesidad de respetar el principio de cumplir o explicar cuando no están previstos este tipo de procedimientos. ${ }^{80}$

No obstante, y pese al gran avance que supone la Directiva, presenta aún indudables déficits. No existe un sistema de auditoria eficiente que supervise la veracidad de la información. Aunque está prevista una auditoria de los balances no financieros, esta se limita a comprobar que efectivamente se ha incluido dicha información, pero sin comprobar su veracidad. Lógicamente un sistema de auditoria eficaz requería, por ejemplo, normas que obligaran a guardar las evidencias sobre las que se basa la información, y criterios más determinados que los actualmente existentes sobre su presentación. En otras palabras, la creación de una suerte de "contabilidad no financiera".

El Reglamento 2017/821 sobre obligaciones en la cadena de suministro de determinados minerales originarios de zonas de conflicto y alto riesgo, aunque limitado a un sector muy concreto, resulta también importante a la hora de establecer un modelo de regulación donde se positivicen las obligaciones de due diligence en materia de Derechos humanos en relación a proveedores. Antes de este Reglamento, y también en el marco de la política comercial común, la UE había aprobado ya otros textos relativos al comercio de diamantes (diamantes de sangre $)^{81} \mathrm{o}$ las cadenas de aprovisionamiento de las empresas madereras, donde el problema principal es el respeto al medio ambiente. ${ }^{82}$ Posteriormente y mediante otros instrumentos de

\footnotetext{
${ }^{78}$ Directrices sobre la presentación de informes no financieros (Metodología para la presentación de información no financiera, DO, 2017, C 215/01, p. 6).

${ }^{79}$ Ampliamente MuÑoz ARENAS/NuÑEZ CHICHARRo, «Los modelos de información no financiera», en Seminario Responsabilidad penal de las empresas multinacionales por violaciones a los Derechos Humanos, Madrid, 13 y 14 de junio de 2019 (http://blog.uclm.es/repmult/).

${ }^{80}$ Directrices sobre la presentación de informes no financieros (Metodología para la presentación de información no financiera, DO, 2017, C 215/01, p. 7: "Las sociedades deben divulgar información significativa sobre los procedimientos de diligencia debida aplicados, que incluya, cuando sea pertinente y proporcionado, información sobre sus cadenas de proveedores y de subcontratación”.

${ }^{81}$ Reglamento (CE) $\mathrm{n}^{\circ}$ 2368/2002 del Consejo, de 20 de diciembre de 2002, por el que se aplica el sistema de certificación del proceso de Kimberley para el comercio internacional de diamantes en bruto, DO L $358 / 28$.

${ }^{82}$ Reglamento (UE) $n^{\circ} 995 / 2010$ de 20 de octubre de 2010, por el que se establecen las obligaciones de los agentes que comercializan madera y productos de la madera, DO L 295/23.
} 
soft law se ha ocupado también de la regulación de cadenas de suministro en el sector textil ${ }^{83} \mathrm{y}$ en las empresas de curtidos. ${ }^{84}$

La preocupación del Reglamento de 2017 nace de la constatación de que muchos conflictos bélicos en el tercer mundo se financian a partir del tráfico con minerales de gran valor y de que además, en la extracción de estos minerales, son muy frecuentes atentados a los Derechos humanos, como la trata de personas, los trabajos forzados o incluso la explotación sexual. En este marco tan determinado, el Reglamento concreta las obligaciones de la empresa líder de la cadena de aprovisionamiento, tomando como punto de partida la Guía de diligencia debida de la OCDE en esta materia. ${ }^{85}$ Los puntos fuertes de esta normativa son que, como ya se ha indicado, incorpora una auditoría externa en la cadena con el fin de comprobar que se cumplen los estándares de diligencia debida. El Reglamento también exige a los Estados realizar inspecciones en las empresas importadoras para comprobar que efectivamente se cumple la normativa. ${ }^{86}$

Los minerales en zonas de conflicto son un buen ejemplo, retrotrayéndonos al debate sobre la complicidad empresarial, del supuesto en que una empresa se aprovecha de las violaciones a Derechos humanos cometidos por un tercero. Pero la normativa de la UE ofrece también algunos ejemplos donde la regulación tiene como objetivo evitar que los clientes de la empresa utilicen los bienes o servicios suministrados con el fin de violar Derechos humanos. Estas disposiciones, a diferencia de los textos anteriores, no guardan una relación tan estrecha con el debate internacional acerca de empresas y Derechos humanos y la estrategia procedente de los Principios. No obstante, y aunque genéticamente tienen un origen diverso, en realidad también recurren -sin nombrarla- a la idea de diligencia debida, vinculada a otras técnicas clásicas de regulación administrativa como son las licencias.

El Derecho de la UE tiene dos bases competenciales distintas. En primer lugar, la Política Exterior y de Seguridad común, de la que proceden numerosas disposiciones (Reglamentos y Decisiones del Consejo) que establecen embargos de armas, productos, servicios e inversiones con países con regímenes que no garantizan los Derechos humanos o en los que existen conflictos armados. ${ }^{87} \mathrm{Al}$ lado de este tipo de medidas, adoptadas en el ámbito de la PESC, existe

${ }^{83}$ Vid. la Iniciativa emblemática de la Unión en el sector de la confección Resolución del Parlamento Europeo, de 27 de abril de 2017, sobre la iniciativa emblemática de la Unión en el sector de la confección (2016/2140(INI)).

84 Vid. Code of Conduct in the Leather and Tanning sector (https://www.eesc.europa.eu/sites/default/files/resources/docs/007-private-act.pdf).

${ }^{85}$ Vid. OECD Due Diligence Guidance for Responsible Supply Chains of Minerals from Conflict-Affected and High-Risk Areas. No obstante, a partir de 2018 la UE ha empezado a reflexionar acerca de un marco global sobre diligencia debida, vid., de un lado, las tomas de postura de la Comisión (Action 10 of the Communication from the Commission to the European Parliament, the European Council, the Council, the European Central Bank, the European Economic and Social Committee and the Committee of the Regions Action Plan: Financing Sustainable Growth, COM/2018/097 final, 8 March 2018) y del Parlamento Europeo (European Parliament Report on Sustainable Finance, 2018/2007(INI)). En enero de 2020 ha aparecido un completo estudio donde se ponen de manifiesto las diferentes opciones regulatorias que pueden adoptarse en este punto, EuRopeAn COMMission, Study on due diligence requeriements through the supply chain. Final Report, 2020.

${ }^{86}$ Vid. DiAgo DiAgo, «El control del comercio internacional de los minerales de conflicto», La Ley, (9099), 2017; GuAMÁN HERnÁNDEZ/Moreno GonZÁLEZ, Empresas multinacionales y Derechos humanos, 2018, pp. 119 ss.

${ }^{87}$ Para tener un listado de las diversas medidas es de gran utilidad: https://www.sanctionsmap.eu/\#/main. 
otras adoptadas sobre la base del art. 207 TFUE (política comercial común), donde se encuentra, por ejemplo, el Reglamento 2019/1258 , que tiene como finalidad regular el comercio con terceros países de productos que puedan utilizarse para aplicar la pena de muerte, penas crueles o infligir torturas $\mathrm{u}$ otros tratos inhumanos o degradantes. El Reglamento prohíbe la exportación, importación y la asistencia técnica cuyo único uso sea contribuir a este tipo de violaciones, incluyendo servicios como el de intermediación, formación o promoción de dichos productos. En el caso de productos de doble uso, el Reglamento establece un régimen de licencias a la exportación, cuyo núcleo consiste precisamente en mostrar que el importador ha establecido las medidas de due diligence adecuadas con el fin de que el bien o servicio no será desviado para un uso ilegal. Estas medias tienen también una base contractual, pues deben formar parte de las cláusulas contractuales entre el fabricante y el distribuidor, con el fin de garantizar que estos productos no van a utilizarse para infligir tortura $u$ otros tratos o penas crueles, inhumanos o degradantes (art. 12.2 y 17 del Reglamento (UE) 2019/15).

Adoptados también en el marco de la política comercial común, encontramos otros reglamentos cuyo objetivo es la protección de los Derechos humanos o de la paz y seguridad. Dejando de lado la normativa sobre tráfico de armas y material nuclear, ${ }^{89} \mathrm{es}$ el caso del Reglamento 428/2009 sobre productos de doble uso. ${ }^{90}$ En estos supuestos, la concesión de una licencia a la exportación también debe estar sometida a controles que caen dentro de la due diligence: conocer cuál será su uso final y el riesgo de desviación, la identidad del usuario final y su localización, así como la existencia en la empresa exportadora de "medios y procedimientos proporcionados y adecuados para asegurar el cumplimiento de las disposiciones y los objetivos del presente Reglamento, así como los términos y las condiciones de la autorización” (art. 10).

\subsection{Delitos y penas en el Derecho penal económico europeo de los DDHH}

La necesidad de un Derecho penal económico que tenga como objeto la protección de bienes jurídicos indispensables para la protección de los Derechos humanos aún no ha sido formulada como tal. ${ }^{91}$ No obstante, como acaba de comprobarse, responde a la evolución de la normativa nacional y supranacional, donde cada vez con más claridad se regula el comportamiento empresarial con el fin de hacer cumplir las obligaciones que las empresas tienen en relación con los Derechos humanos. Algunas partes de esta nueva rama del Derecho penal económico existen desde hace años, si bien hasta ahora no se ha mostrado directamente su vinculación con los Derechos humanos, lo que sin duda las ha relegado a un segundo plano.

\footnotetext{
${ }^{88}$ Reglamento (UE) 2019/125 del Parlamento europeo y del Consejo, de 16 de enero de 2019, sobre el comercio de determinados productos que pueden utilizarse para aplicar la pena de muerte o infligir tortura u otros tratos o penas crueles, inhumanos o degradantes, DO 2019 L 30/1.

${ }^{89}$ Vid. GARROCHO SALCEDO, «Responsabilidad penal en el suministro de armas», en Seminario Internacional sobre responsabilidad penal de empresas multinacionales por violaciones de los derechos humanos, Madrid, 13 y 14 de junio 2019 (http://blog.uclm.es/repmult/).

${ }^{90}$ Reglamento (CE) no 428/2009 del Consejo, de 5 de mayo de 2009, por el que se establece un régimen comunitario de control de las exportaciones, la transferencia, el corretaje y el tránsito de productos de doble uso.

${ }^{91}$ Vid. no obstante las novedosas y decisivas ideas que en este punto avanza MonGILLO, Revista trimestrale di Diritto penale dell'economia, (3-4), 2019, pp. 667 ss.
} 
En Alemania el denominado Derecho penal del comercio exterior ${ }^{92}$ o en España los delitos de contrabando castigan las violaciones al régimen de embargos, la exportación de armas, productos de doble uso o elementos que pueden ser utilizados en la imposición de la pena de muerte. ${ }^{93}$ No obstante, es dudoso que estas infracciones que en líneas generales tienen como bien protegido la capacidad de control que el Estado tiene en sus fronteras, capten adecuadamente el desvalor de estas conductas. De este modo, resulta necesario reflexionar sobre una nueva generación de infracciones que tengan en cuenta los avances de la regulación, estableciendo obligaciones positivas de protección de los Derechos humanos y que complementen a las disposiciones clásicas de Derecho penal internacional.

\section{a. Receptación de bienes o servicios producidos con violaciones a los $\mathrm{DDHH}$}

El delito de receptación de bienes o servicios producidos con violaciones a los Derechos humanos constituiría una de las infracciones más importantes. ${ }^{94} \mathrm{Al}$ igual que ocurre con el delito de "receptación" y con el blanqueo de capitales, su bien jurídico protegido sería el mismo que el que tienen los delitos de los que proceden los bienes (vgr. la trata de personas). Podría hablarse incluso de un bien jurídico de carácter supraindividual como es la existencia de un comercio internacional libre de violaciones a los Derechos humanos, que nuevamente, trazando un paralelismo con el blanqueo, comprendería también la protección de la competencia leal. La utilización de productos o servicios producidos por empresas que utilizan prácticas como el trabajo forzado o infantil otorga una ventaja anticompetitiva, que el resto puede acabar imitando.

Un tipo penal que castigase de manera general este comportamiento no sería conforme al mandato de determinación penal, por esta razón debe irse formulando de manera paulatina en sectores específicos, donde exista un grado de concreción suficiente de las medidas de due diligence en la cadena de suministro. La sanción penal del incumplimiento de los deberes de due diligence debiera servir para que las empresas redujeran en la medida de lo posible sus cadenas de suministro. Es un hecho comprobado que los riesgos de violaciones aumentan a medida que la cadena aumenta. ${ }^{95}$

Una nota común a esta normativa, y en general a todo el Derecho penal económico de los Derechos humanos, es que, como hemos visto en el Reglamento sobre minerales en zonas de conflicto constituyen un nuevo tipo de normas penales en blanco, en el cual las remisiones normativas se harán generalmente al soft law promulgado por organizaciones internacionales. Es lo que ocurre, como hemos visto, en el Reglamento sobre los minerales en zonas de conflicto. Con ello se consigue que las medidas de cumplimiento sean globales, al provenir de organismos con la OCDE o Naciones Unidas, pero dada la menor transparencia de los procesos de generación de soft law de las organizaciones internacionales existe mayor peligro, por

\footnotetext{
${ }^{92}$ Cfr. Tiedemann, Wirtschaftsstrafrecht, 5a ed., 2017, pp. 249 ss. (= Tiedemann, Manual de Derecho penal económico, 2010, pp. 251 ss.).

${ }^{93}$ Vid. art. 2 1. d), art. 2.2. c) $1^{\circ}$ y $2^{\circ}$ de la Ley 12/1995 de Represión del contrabando; vid. al respecto NiETO Martín, «Lección XIV», en Gómez Rivero (dir.), Manual de Derecho Penal. Parte Especial, v. II, $3^{\text {a }}$ ed., 2019, pp. 362 y 368, señalando la vinculación entre estos los delitos de contrabando y la protección de los Derechos humanos.

${ }^{94} \mathrm{La}$ creación de este delito ha sido propuesta públicamente por el Prof. Jacobo Dopico en varias conferencias y seminarios. Recientemente propone también un precepto penal de similares características, Mongillo, Revista trimestrale di Diritto penale dell'economia, (3-4), 2019, pp. 669 ss.

${ }^{95}$ Cfr. Mongillo, Revista trimestrale di Diritto penale dell'economia, (3-4), 2019, p. 670.
} 
ejemplo, de influencias de lobbies. Existe, por tanto, un problema de legitimidad al que es preciso atender. ${ }^{96}$

En su tipo subjetivo, con una estructura que recuerda al blanqueo de capitales, los delitos de receptación de bienes o servicios procedentes de violaciones de Derechos humanos deben establecer dos modalidades típicas: de un lado, la violación dolosa de estas obligaciones de cumplimiento normativo con el fin de aprovisionarse de bienes o servicios, de otro, en el caso más frecuente, el aprovisionamiento imprudente, infringiendo gravemente las obligaciones de diligencia debida. ${ }^{97}$

Este tipo penal tendría generalmente carácter subsidiario a los casos en donde pueda apreciarse una verdadera complicidad empresarial, cuando la adquisición del bien o servicio por parte de la empresa pueda considerarse que facilita significativamente la violación de Derechos humanos en un caso concreto. Este podría ser el caso, por ejemplo, en que la empresa adquiere la totalidad o gran parte, pongamos por caso, de los minerales de una empresa, conociendo que en su producción existe trata de personas.

\section{b. Embargos y exportaciones condicionadas al cumplimiento de deberes de due diligence}

La segunda tipología de tipos penales pertenecientes al Derecho penal económico de los Derechos humanos tendría que ver con los casos también cercanos a la complicidad empresarial como es el suministro de bienes y servicios. En este punto, y siguiendo la técnica que utiliza la normativa europea, habría que distinguir entre prohibiciones absolutas de exportar un determinado bien o prestar un servicio y exportaciones o prestaciones de servicios sometidas a determinadas condiciones, como singularmente obtención de licencias, que como hemos visto suelen ir acompañadas de obligaciones de due diligence (arts. 12.2 y 17 del Reglamento (UE) 2019/15). ${ }^{98}$ Para ganar en efectividad, estos tipo penales deberían abarcar aquellas situaciones en que, pese a haber obtenido una licencia válida y cumplir en este momento las obligaciones de diligencia debida, estas después se incumplen sistemáticamente.

La existencia de esta normativa, como ya se ha indicado, establece el marco de riesgo permitido dentro del cual puede considerarse este tipo de operaciones neutrales y por tanto no relevantes desde el punto de vista de la complicidad con las personas autoras directas de la violación. ${ }^{99}$ Esto, desde luego, no implica que automáticamente pueda hablarse de una complicidad en la violación de Derechos humanos realizada por un tercero, pues es necesario comprobar, por ejemplo, que en el caso concreto ha existido una efectiva facilitación o favorecimiento del hecho. Los tipos penales de violaciones de embargos o suministros de bienes o servicios

\footnotetext{
${ }^{96}$ Cfr. Nieto Martín, en Nieto Martín/García Moreno (dirs.), Ius puniendi y global law. Hacia un Derecho penal sin Estado, 2019, pp. 78 ss., 91 ss.

${ }^{97}$ Dubitativo en relación a la introducción de una modalidad imprudente MonGILLO, Revista trimestrale di Diritto penale dell'economia, (3-4), 2019, p. 671.

${ }^{98} \mathrm{El}$ que se trate de controlar no solo el tráfico de bienes, sino también la prestación de servicios o inversiones, muestra en este punto lo insuficiente y caduco de la óptica de los delitos de contrabando para sancionar este tipo de conductas.

${ }^{99}$ P.ej., el dirigente policial que ha ordenado que un dispositivo policial utilizado "para hacer cumplir la ley”, se modifique con el fin de convertirlo en un instrumento de tortura o con el dirigente político que utiliza un producto utilizado para la sedación de pacientes como un componente dentro de la inyección letal en la ejecución de la pena de muerte.
} 
condicionados a la due diligence servirán, por tanto, como tipo de recogida en caso de que no pueda aplicarse la complicidad empresarial. ${ }^{100}$

c. Incumplimiento genérico de las obligaciones de due diligence

Un precepto clave en el Derecho penal económico de los Derechos humanos sería la ausencia de medidas de due diligence o su adopción defectuosa, cuyo bien jurídico sería la protección del interés estatal en que exista una autorregulación eficaz en materia de Derechos humanos. ${ }^{101}$ No obstante, en este punto lo acaecido con la Ley de vigilancia empresarial francesa muestra que formular un precepto que sancione genéricamente la infracción de las obligaciones de cumplimiento normativo en materia de Derechos humanos plantea numerosos problemas constitucionales. Como hemos visto, la Ley francesa establece la obligación legal para las grandes empresas de contar con programas de cumplimiento en este ámbito, ofreciendo en su art. L. 225-102-4 sus elementos esenciales. Pese a esta concreción de las obligaciones de cumplimiento normativo, el Consejo constitucional francés consideró que esta sanción administrativa no era respetuosa con el principio de determinación declarándola inconstitucional, ${ }^{102}$ fundamentalmente porque consideró impreciso el objeto sobre el que debe versar el programa (¿cuáles eran concretamente los derechos afectados?, ¿qué proveedores tenían que someterse a la obligación de debido control?, etc.) y la determinación de la sanción. Por esta razón, la formulación de este tipo penal, respetando el mandato de determinación, debiera limitarse a aquellos sectores en donde existe ya una concreción suficientemente precisa de las medidas que debe adoptar la empresa. ${ }^{103}$

En este sentido, se ha propuesto una infracción, por ejemplo, en materia de trata de personas y trabajo forzado, semejante a la failure to prevent bribery de la Bribery Act del Reino Unido. ${ }^{104}$ La principal cualidad de esta infracción es que admite que el delito puede ser cometido por personas que prestan servicios a la organización, lo que solventaría el problema de la imputación a la persona jurídica de las infracciones cometidas por proveedores a los que tenga la obligación de controlar. No obstante, esta figura no tendría por qué ir vinculada en exclusiva a la realización de comportamientos dolosos o imprudentes de terceros. Un ámbito de aplicación importante serían los casos en que existe una afectación a Derechos humanos que no necesariamente puede encajar en un tipo penal, pero que la empresa tiene la obligación de prevenir. Igualmente, para garantizar una obligación de autorregulación tan específica, podrían sancionarse directamente a los dirigentes empresariales que las han incumplido.

La existencia de una obligación de autorregulación en Derechos humanos y su correspondiente sanción penal necesitaría en cualquier caso de una supervisión pública que fuera concretando las obligaciones de las empresas. En definitiva, se trataría de un cometido similar al que tienen agencias anticorrupción como la francesa, que podrían asumir en un futuro las agencias de Derechos humanos.

\footnotetext{
${ }^{100}$ Así ya TiEDEMANN, Wirtschaftsstrafrech, 2017, p. 263, en relación al Außenwirtschaftsstrafrecht.

${ }^{101}$ Sobre la existencia de un bien jurídico consistente en el interés estatal a la autorregulación, vid. GóMEZ Tomillo, Compliance Penal y política legislativa, 2016.

${ }^{102}$ Conseil Constitutionnel No 2017-750, de 23 de marzo.

${ }^{103}$ Vid. SCHEPER/Grabosch, Die menschenrechtliche Sorgfaltspflicht von Unternehemen, 2015, pp. $30 \mathrm{~s}$.

${ }^{104}$ En este sentido también Mongillo, Revista trimestrale di Diritto penale dell'economia, (3-4), 2019, pp. 672 ss.
} 


\section{d. La falsedad en el balance no financiero}

Otro camino posible con el fin de incitar a través de sanciones a que las empresas adopten programas de cumplimiento normativo en materia de Derechos humanos es sancionar la falsedad en los balances no financieros. ${ }^{105}$ Con una lógica en cierto modo similar ya se había propuesto, por ejemplo, sancionar como práctica desleal el incumplimiento doloso de códigos éticos que la empresa decía respetar dentro de sus políticas de responsabilidad social ${ }^{106}$ y algo similar había ocurrido en los Estados Unidos con el asunto Nike. ${ }^{107}$

La información no financiera, que comprende aspectos como la gobernanza o la composición del accionariado, cada vez tiene un mayor peso en los mercados. La transparencia de aspectos como los compromisos de las empresas para no afectar a los Derechos humanos puede ser de gran importancia para fondos de inversión éticos, pero también un criterio a tener en cuenta para evaluar su nivel de riesgos o la calidad de su gestión. De la Directiva sobre información financiera no puede desprenderse en modo alguno que este tipo de información sea de segundo nivel. Por esta razón, la obligación existente en el art. 51 de la Directiva sobre los estados financieros anuales de establecer sanciones proporcionadas, disuasivas y eficaces, pesa también sobre los estados miembros. La STJU de 3 de mayo de 2005 (caso Berlusconi) determinó con claridad que estas sanciones debían ser suficientemente graves, lo que de facto podía ser interpretado como una obligación de que estas sean de carácter penal.

En algunos países de la UE la información no financiera y, concretamente, la que abarca a los programas de cumplimiento en materia de Derechos humanos se sanciona ya de este modo. Es el caso, por ejemplo, de Alemania donde el § 334.3 (a) HGB sanciona con multad de hasta 10 millones de Euros o el cinco por ciento del total de negocios en el último año su incumplimiento. ${ }^{108}$ Por otro lado, la vinculación entre transparencia y medidas de diligencia era precisamente el camino adoptado en relación al tráfico de personas en la Modern Slavery Act o en la Ley de california. Un precepto de estas características será tanto o más efectivo a medida que vayan concretándose, bien legalmente bien por la vía del soft law, la forma en que han de confeccionarse los balances no financieros, y se vayan imponiendo obligaciones colaterales como la necesidad de conservar determinada información, que permita confirmar la veracidad de lo afirmado en ellos, o se incremente la obligación de auditarla que hasta ahora resulta muy reducida.

\section{e. La responsabilidad de los certificadores y auditores}

El papel de las empresas certificadoras y auditoras resulta esencial en todo el sistema de cumplimiento normativo en Derechos humanos, sobre todo porque aseguran el cumplimiento de la normativa nacional o de determinados estándares allí donde no existen servicios estatales

\footnotetext{
${ }^{105}$ Vid. ya Nieto MARTín, «La autorregulación preventiva de la empresa como objeto de la política criminal», en SiLva SÁNCHEz et al (coords.), Derecho penal del Estado Social y Democrático de Derecho. Libro Homenaje a Santiago Mir Puig, 2017, pp. 167 ss. Igualmente, FofFANI, «Falsedad en los estados no financieros», en Seminario Internacional sobre responsabilidad penal de empresas multinacionales por violaciones de los Derechos humanos, Madrid, 13 y 14 de junio de 2019 (http://blog.uclm.es/repmult/). 106 Art. 5 Directiva 2005/29, relativa a prácticas comerciales desleales, DO L 149/22.

${ }^{107}$ Al respecto, Williams, «The Securities Exchange Commission and Corporate Social Transparency», Harvard Law Review, (112), 1999, pp. 112 ss.

108 Cfr. Tiedemann, Wirtschaftsstrafrecht, 2017, p. 481.
} 
de supervisión. Tanto el Reglamento de la UE sobre minerales en zonas de conflicto, como anteriormente, el Reglamento de "diamantes de sangre", consideran la certificación y la auditoria como una de las herramientas claves de la due diligence en materia de Derechos humanos. Aunque las inspecciones realizadas por la propia empresa a los locales de la proveedora, puedan ser la medida más eficaz, esto no siempre es posible, y tampoco excluye la función de la certificación en la fase previa de selección del proveedor. Una parte esencial en el debate debe ser cómo mejorar la capacidad de certificación y auditoría, para lo que habría que comenzar con asegurar al certificador/auditor un estatus de independencia similar a la auditoría de cuentas e igualmente señalar cuáles son sus deberes de denuncia o, lo que es de gran importancia, cómo asegurar la calidad de las certificadoras que actúan en diversas partes del mundo. De manera inmediata, esto podría implicar que al menos los auditores en materia de Derechos humanos fueran también elegidos por las comisiones de auditoría de las sociedades cotizadas.

En alguno de los casos más graves de violaciones a Derechos humanos ha aparecido la cuestión de la responsabilidad penal de las empresas certificadoras. En el caso del incendio de la fábrica Ali Enterprises en Pakistán, que albergaba a una industria textil proveedora de empresas europeas, se ha planteado la responsabilidad penal de la sociedad certificadora italiana que había emitido la SA 8000 que asegura el cumplimiento de las normas de salud laboral. ${ }^{109}$ Igualmente en el caso de la catástrofe medioambiental de Brumandinho en Brasil, protagonizada por la empresa minera Vale, la fiscalía brasileña acusa de los delitos medioambientales y homicidio a la sociedad certificadora alemana, que había auditado las condiciones de seguridad de la presa, cuya ruptura provocó la catástrofe medioambiental. ${ }^{110}$

La responsabilidad penal y civil de las certificadoras debe constituir uno de los debates principales del Derecho penal económico de los Derechos humanos. Desde el punto de vista civil resulta, por ejemplo, dudoso que las certificadoras/auditoras tengan una obligación de prevenir daños a terceros y desde luego no guardan relación contractual normalmente con la empresa a la que se suministran los servicios, por lo que no está nada claro cuál es su responsabilidad en relación a daños a terceros. ${ }^{111}$ Por esta razón debiera discutirse por ejemplo la necesidad de un tipo penal que sancionara la falsedad en las certificaciones, incluyendo desde luego la falsedad imprudente.

\section{f. La competencia de la UE}

El conjunto de infracciones que acaban de diseñarse a grandes rasgos podrían ser objeto de armonización a través del Derecho de la Unión. Como se ha señalado anteriormente, el fundamento de estas normas se encuentra en el marco de la Política Exterior y de Seguridad Común, en el marco de la política comercial común, que es competencia exclusiva además del Derecho de la Unión, o en la regulación relativa a la libertad de establecimiento. En todos estos casos podría invocarse la competencia anexa prevista en el art. 83.2 TFUE para proceder a la armonización. La vía del art. 83.1 TFUE podría ser también la adecuada en relación a medidas destinadas a prevenir el tráfico de personas, la explotación sexual o el tráfico de armas, delitos

\footnotetext{
${ }^{109} \mathrm{Cfr}$. ECCHR, After factory fire in Pakistan: proceedings against auditor in Italy criminal proceedings and OECD complaint against certifier Rina (https://www.ecchr.eu/en/case/after-factory-fire-in-pakistanproceedings-against-auditor-in-italy/).

${ }^{110}$ Vid. https://elpais.com/internacional/2020/01/22/actualidad/1579719454_545898.html.

${ }^{111}$ Cfr. SCHEPER/GRABOSCH, Die menschenrechtliche Sorgfaltspflicht von Unternehemen, 2015, pp. $55 \mathrm{~s}$.
} 
todos que en sus modalidades más graves pueden conllevar una afectación a los Derechos humanos. ${ }^{112}$

La necesidad de recurrir a sanciones penales con el fin de asegurar las obligaciones de due diligence de las empresas multinacionales es algo que se repite también en los Principios de Naciones Unidas. Si hasta ahora no se ha dado ningún paso en este sentido, al menos en la UE, probablemente tiene que ver con el hecho de que esta materia se ha vinculado tradicionalmente a la Responsabilidad Social Corporativa. En lo tocante a la protección de Derechos humanos, tanto el Tribunal Europeo de Derechos humanos, como la Corte Interamericana han subrayado además que contar con un Derecho penal eficaz, que sancione las violaciones, forma parte de la obligación de "proteger" que pesa sobre los Estados. Debe, no obstante, debatirse si esta jurisprudencia que se refiere a violaciones directas puede trasladarse a estas infracciones situadas en el ámbito previo. ${ }^{113}$

Cuestión distinta es que, conforme al principio de subsidiariedad, deba dejarse en primer término en manos de los Estados miembros la articulación de estas nuevas infracciones dentro de su Derecho penal económico. No obstante, en este punto debe tenerse en cuenta que estas infracciones cumplen con criterios como la gravedad y la transnacionalidad.

\section{Bibliografía}

ÁLVAREZ TORNÉ (2015), «Tendencias actuales en Materia de responsabilidad civil internacional por vulneraciones de derechos humanos cometidas por empresas», Revista española de Derecho internacional, (67), pp. 291 ss.

Ambos (2018), «International Economic Criminal Law», Criminal Law Forum, (29), 2018, pp. 499 ss.

\section{(2018), Derecho penal internacional económico, Civitas, Madrid, 2018.}

Ambos/CARSTEn (eds.) (2018), «Special Issue: Human Rights Compliance and Corporate Criminal Liability», Criminal Law Forum, (4), pp. 495 ss.

Aмвоs/Bоск (2018), Aktuelle und grundsätzliche Frages des Wirtschaftsvölkerstrafrecht, Duncker \& Humboldt, Berlin.

ARENAl LoRa (2019), Crímenes económicos en Derecho internacional: Propuesta de una nueva categoría de crímenes contra la humanidad, Aranzadi, Pamplona.

\footnotetext{
${ }^{112}$ Sobre las competencias armonizadoras de la UE, MuÑoz De MoRALES, Derecho penal europeo, 2020, pp. 39 ss.

${ }^{113}$ Sobre esta cuestión últimamente VALIENTE LANUZA, «Deberes positivos del Estado y Derecho penal en la jurisprudencia del TEDH», Indret, (3), 2016.
} 
Business AND Humann Rights Resource Center (2017), Modern Slavery in Company Operations and Supply Chains, Madantory Transparence, Mandatory Due Diligence and Public Procurement.

BUSEKIST/DimisC (2018), «Compliance als Instrument der Menschenrechtsshutzes», en KRAJEWSKI/OEHM/SAAGE-MAAß (eds.), Zivil- und Strafrechtliche Unternehmensverantwortung für Menchenrechtsverletzungen, Springer, Berlin/Heidelberg, pp. 267 ss.

CASSEL (2014), «Suing Americans For Human Rights Torts Overseas: The Supreme Court Leaves The Door Open», Notre Dame Law Review, (4), pp. 1773 ss.

(2008), «Corporate Aiding and Abetting of Human Rights Violations: Confusion in the Courts», Northwestern Journal Of International Human Rights, (6), pp. 1 ss.

CASTILlo MonterRey (2014), «El expolio de las riquezas nacionales: un nuevo reto para el Derecho Penal Internacional», en DEMETRIO CRESPO (dir.), Crisis financiera y derecho penal económico, BdeF, Buenos Aires, pp. 211 ss.

De Brito Gueiros/De Alencar E Miranda (2017), «Brazilian Report on Individual Liability for Business Involvement in International Crimes», en MANACORDA/MARLETA/VANACORE (eds.), «Individual Liability for Business Involvement in International Crimes», Revue Internationale de Droit Pénal, (1), pp. 141 ss.

De Schutter/Ramasastry/Taylor/Thompson (2012), Human Rights Due Diligence: The Role Of States.

DE VICENTE (2018), «Hacia un derecho penal medioambiental: catástrofes ambientales y ecocidio», en Demetrio CRESPo/NieTo MARTín (dirs.), Derecho penal económico y Derechos humanos, Tirant lo Blanch, Valencia, pp. 245 ss.

Demetrio CRespo/Nieto MarTín (dirs.) (2018), Derecho penal económico y Derechos humanos, Tirant lo Blanch, Valencia.

DiAGo DiAGo (2017), «El control del comercio internacional de los minerales de conflicto», $L a$ Ley, (9099).

EICKENJÄGER (2018), «Die Durchsetzung von Menschenrechten gegenüber Unternehmen mittels nichtfinanzieller Berichterstattung», en KRAJEWSKI/SAAGE-MAAß (eds.), Die Durchsetzung menschenrechtlicher Sorgfaltspflichten von Unternehmen, Nomos, Baden-Baden, pp. 243 ss.

EUROPEAN COMMISSION (2020), Study on due diligence requeriements through the supply chain. Final Report. 
FOFFANI (2019), «Falsedad en los estados no financieros», en Seminario Internacional sobre responsabilidad penal de empresas multinacionales por violaciones de los Derechos humanos, Madrid, 13 y 14 de junio (http://blog.uclm.es/repmult/).

FORCADA BARONA (2018), «Derechos internacional, responsabilidad social corporativa y derechos humanos», en Demetrio CReSPo/Nieto MARTín (dirs.), Derecho penal económico y Derechos humanos, Tirant lo Blanch, Valencia, pp. 53 ss.

GaRCía SEDANo, Una aproximación desde el Derecho internacional y el Derecho comparado a la regulación de las cadenas de suministro y las formas contemporáneas de esclavitud (en prensa).

GARROCHO SALCEDO (2019), «Responsabilidad penal en el suministro de armas», en Seminario Internacional sobre responsabilidad penal de empresas multinacionales por violaciones de los derechos humanos, Madrid, 13 y 14 de junio (http://blog.uclm.es/repmult/).

(2016), La responsabilidad del superior por omisión en el Derecho penal internacional, Aranzadi, Pamplona.

Gómez Tomillo (2016), Compliance Penal y política legislativa, Tirant lo Blanch, Valencia.

GuAMÁN HERNÁNDEZ/MoRENo GonZÁLEZ (2018), Empresas multinacionales y Derechos Humanos, Bomarzo, Albacete.

HESS (2007), «Social reporting and new gobernance regulation: the prospects of achieving corporate accountability through transparency», Businness Ethics Quartely, (3), pp. 453 ss.

HORST (2018), «Shareholder Activism for Human Rights? Aktienrechtliche Instrumente zur mittelbaren Duchsetzung von Menschenrechtspflichte auf den Finanzmärken», en en Krajewski/SaAge-MaAß (eds.), Die Durchsetzung menschenrechtlicher Sorgfaltspflichten von Unternehmen, Nomos, Baden-Baden, pp. 203 ss.

HÜBNER (2018), «Human Rights Compliance um Haftung im Außenverhältnis», en Krajewski/SaAge MaAB (eds.), Die Durchsetzung menschenrechtlicher Sorgfaltspflichten von Unternehmen, Nomos, Baden-Baden, pp. 61 ss.

JEßBERGER/KALECK/SINGELNSTEIN (eds.) (2015), Wirtschaftsvölkerstrafrecht. Ursprünge, Begriff, Praxis, Perspektiven, Nomos, Baden-Baden.

JOSEPH (2004), Corporations and Transnational Human Rights Litigations, Hart Publishing, Oxford. 
KALECK (2015), «Die Verantwortung von Unternehmen und Unternehmern für Völkerrechtsverbrechen -die Nüremberg Prozessen», en JEßBERGER/KALECK/SINGELNSTEIN (eds.), Wirtschaftsvölkerstrafrecht. Ursprünge, Begriff, Praxis, Perspektiven, Nomos, Baden-Baden, pp. 83 y ss.

KLINGER/KRAJEWSKI/KREBS/HARTMANN (2016), Verankerung menschenrechtlicher Sorgfaltspflichten von Unternehmen in deutschen Recht (https://www.oxfam.de/system/files/gutachtensorgfaltspflichten-oxfam.pdf).

Krajewsil/Oehm/SAage-MaAß (eds.) (2018), Zivil- und Strafrechtliche Unternehmensverantwortung für Menchenrechtsverletzungen, Springer, Berlin/Heidelberg.

LAFUENTE (2002), Esclavos por la patria. La explotación de los presos bajo el franquismo, Temas de Hoy, Barcelona.

LASCURAIN SÁNCHEZ (2018), «Tema 3. La responsabilidad penal individual en los delitos de empresa», en DE LA MATA /Dopico/LASCURAín/NieTo, Derecho penal económico y de la empresa, Dykinson, Madrid, pp. 87 ss.

MANACORDA (2017), «General Report on Individual Liability for Business Involvement in International Crimes», en MANACORDA/MARLETA/VANACORE (eds.), «Individual Liability for Business Involvement in International Crimes», Revue Internationale de Droit Pénal, (1), pp. 22 ss.

MANACORDA/MARLETA/VANACORE (eds.) (2017), «Individual Liability for Business Involvement in International Crimes», Revue Internationale de Droit Pénal, (1).

MARLETTA (2017), «Heads of Business and the framework of Liability for complicity under International Criminal Law», en MANACORDA/MARLETA/VANACORE (eds.), «Individual Liability for Business Involvement in International Crimes», Revue Internationale de Droit Pénal, (1), pp. 91 ss.

Martínez-Bujan PéRez (2016), Derecho penal económico y de la empresa. Parte General, $5^{\mathrm{a}}$ ed., Tirant lo Blanch, Valencia.

MARZEN (2010), «The Furundzija Judgment And Its Continued Vitality In International Law», Creighton Law Review, (43), pp. 505 ss.

MoNGILLO (2019), «Forced Labour e sfruttamento lavorativo nella catena di fornitura dell'imprese: strategie global di prevenzione e reppresione», Revista trimestrale di Diritto penale dell'economia, (3-4). 
MUÑOZ ARENAS/NuÑEZ CHICHARRo (2019), «Los modelos de información no financiera, en Responsabilidad penal de las empresas multinacionales por violaciones a los Derechos Humanos», en Seminario Internacional sobre responsabilidad penal de empresas multinacionales por violaciones de los Derechos humanos, Madrid, 13 y 14 de junio (http://blog.uclm.es/repmult/).

MuÑoz De Morales (2020), Derecho penal europeo, Tirant lo Blanch, Valencia.

NAUCKE (2012), Der Begriff der politischen Wirtschaftsstraftat. Eine Annäherung, Lit, Münster.

NEYERT (dir.) (2015), Des écocrimes à l'ecocide. Le droit penal au secours de l'environnement, Bruylant, Bruselas.

Nieto MarTín (2019), «Transformaciones del ius puniendi en el Derecho global», en Nieto Martín/García Moreno (dirs.), Ius puniendi y global law. Hacia un Derecho penal sin Estado, Tirant lo Blanch, Valencia.

(2019), «Lección XIV», en Gómez Rivero (dir.), Manual de Derecho Penal. Parte Especial, v. II, $3^{\mathrm{a}}$ ed., Tecnos, Madrid.

(2018), «La responsabilidad penal de empresas multinacionales y la seguridad alimentaria», en DeMETRIO CRESPO/NieTO MARTIN, Derecho penal económico y Derechos humanos, Tirant lo Blanch, Valencia.

(2017), «Empresas, víctimas y sanciones restaurativas: ¿cómo configurar un sistema de sanciones para personas jurídicas pensando en sus víctimas?», en DE HoYos SANCHO (coord.), La víctima del delito y las últimas regulaciones procesales penales, Aranzadi, Pamplona, pp. 315 ss.

(2017), «La autorregulación preventiva de la empresa como objeto de la política criminal», en SILVA SÁNCHEZ et al (coords.), Derecho penal del Estado Social y Democrático de Derecho. Libro Homenaje a Santiago Mir Puig, pp. 167 ss.

(dir.) (2013), Manual de cumplimiento penal en la empresa, Tirant lo Blanch, Valencia.

(2012), «Bases para un futuro Derecho penal internacional del medio ambiente», Anuario de la Facultad de Derecho de la Universidad Autónoma de Madrid, (16), pp. 137 ss.

PÉREZ CEPEDA (2019), «Hacia el final de la impunidad de las empresas transnacionales por violación de Derechos Humanos», Revista Penal, (44), pp. 126 ss. 
(2018), «Acuerdos de libre comercio y el sistema internacional de Derechos Humanos en el marco del Derecho penal internacional», en DE LA CuESTA et al. (dirs.), Liber amicorum. Estudios jurídicos en homenaje al Prof. Dr. h. c. mult. Juan Terradillos Basoco, Tirant lo Blanch, Valencia.

PIETH (2018), «Corporate compliance and Human Rights», Criminal Law Forum, (29), pp. 595 ss.

REQUEJO ISIDRO (2009), Violaciones graves de derechos humanos y responsabilidad civil, Aranzadi, Pamplona.

SAAD DINIZ (2019), Victimología corporativa, Tirant lo Blanch, Valencia.

SAAGE-MAAS (2018), «The Merowe Dam Project- When does the coin flip from legal business activity to criminal behaviour? Reflections on the concept of guarantor's liability in the context of transnational business activities», Criminal Law Forum, (29), pp. 603 ss.

SCAHILl (2008), Blackwater: el auge del ejército mercenario más poderoso del mundo, Paidós, Bacelona.

SCHEPER/GRABOSCH (2015), Die menschenrechtliche Sorgfaltspflicht von Unternehemen, Friedrich Ebert Stiftung, Berlin.

SCHMIDT (2006), Crimes of Business in International Law, Nomos, Baden-Baden.

THOMPSON/RAMASASTRY/TAYLOR (2009), «Translating Unocal: The Expanding Web Of Liability For Business Entities Implicated In International Crimes», George Washington International Law Review, (40), pp. 841 ss.

THURNER (2012), Internationales Unternehmensstrafrecht. Konzerverantwortlichkeitkeit für schwere Menschenrechtsverletzungen, Österreich, Viena.

Tiedemann (2017), Wirtschaftsstrafrecht, $5^{\text {a }}$ ed., Vahlen, Múnich.

(2010), Manual de Derecho penal económico, Tirant lo Blanch, Valencia.

VALIENTE LANUZA (2016), «Deberes positivos del Estado y Derecho penal en la jurisprudencia del TEDH», Indret. Revista para el análisis del Derecho, (3).

Williams, «The Securities Exchange Commission and Corporate Social Transparency», Harvard Law Review, (112), pp. 1197 ss. 
WiTTIG, «Zur Legitimation und Grenzen eines rechtsstastaatlichen Wirtschaft» en JEßBERGER/KALECK/SINGELNSTEIN (eds.), Wirtschaftsvölkerstrafrecht. Ursprünge, Begriff, Praxis, Perspektiven, Nomos, Baden-Baden, pp. 246 ss.

ZÚÑIGA RODRÍGUEZ (2018), «Responsabilidad penal de las personas jurídicas y derechos humanos. Una valoración desde la reforma de 2015 de la legislación española», en DEMETRIO CRESPo/NieTo MARTín (dirs.), Derecho penal económico y Derechos humanos, Tirant lo Blanch, Valencia, pp. 87 ss. 